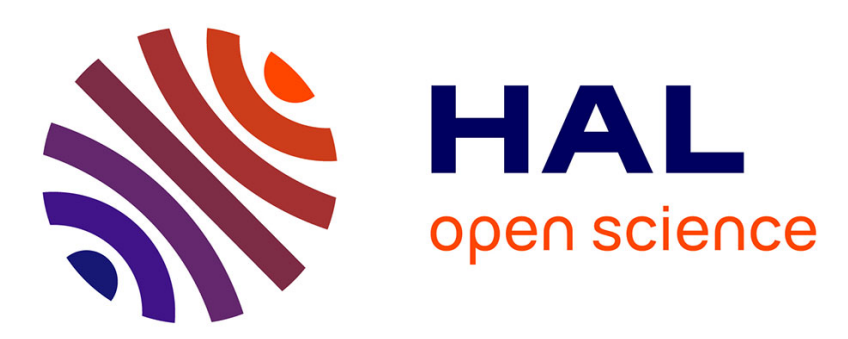

\title{
The influence of codoping on optical properties and glass connectivity of silica fiber preforms
}

Maria Rita Cicconi, Wilfried Blanc, Dominique de Ligny, Daniel R. Neuville

\section{To cite this version:}

Maria Rita Cicconi, Wilfried Blanc, Dominique de Ligny, Daniel R. Neuville. The influence of codoping on optical properties and glass connectivity of silica fiber preforms. Ceramics International, 2020, 46 (16), pp.26251-26259. 10.1016/j.ceramint.2020.05.233 . hal-02989463

\section{HAL Id: hal-02989463 https://hal.science/hal-02989463}

Submitted on 12 Nov 2020

HAL is a multi-disciplinary open access archive for the deposit and dissemination of scientific research documents, whether they are published or not. The documents may come from teaching and research institutions in France or abroad, or from public or private research centers.
L'archive ouverte pluridisciplinaire HAL, est destinée au dépôt et à la diffusion de documents scientifiques de niveau recherche, publiés ou non, émanant des établissements d'enseignement et de recherche français ou étrangers, des laboratoires publics ou privés. 


\section{The influence of codoping on optical properties and glass}

\section{2 connectivity of silica fiber preforms.}

3

4

5

6

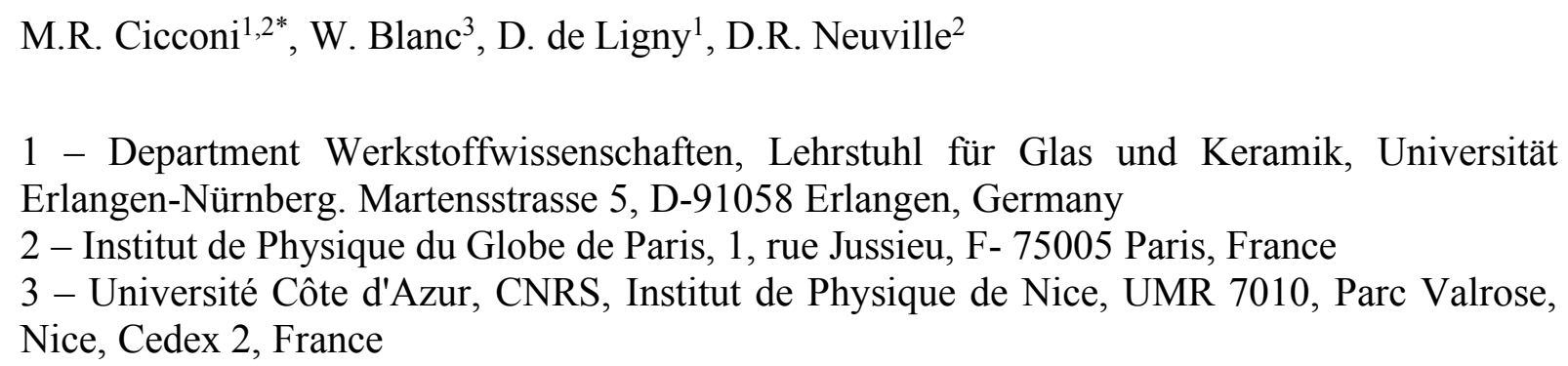

Keywords: REE, Raman, Photoluminescence, glass structure, cations structural role

*Corresponding author: Dr. Maria Rita Cicconi

e-mail: maria.rita.cicconi@,fau.de

phone: +49 $913185-27567$

Friedrich-Alexander-Universität Erlangen-Nürnberg, Martensstrasse 5, D-91058, Erlangen (Germany)

The authors declare that they have no known competing financial interests or personal relationships that could have appeared to influence the work reported in this paper.

\section{Confirmation of Authorship}

As corresponding author, I Maria Rita Cicconi, hereby confirm on behalf of all authors that this manuscript is original and unpublished, and is not being or having been submitted for publication to any other journal, and that all the authors have read the manuscript and agree with its submission to Ceramics International.

Dr. Maria Rita Cicconi 
 \\ The influence of codoping on optical properties and glass connectivity of
}

33

34 silica fiber preforms.

\author{
M.R. Cicconi ${ }^{1,2 *}$, W. Blanc ${ }^{3}$, D. de Ligny ${ }^{1}$, D.R. Neuville ${ }^{2}$
}

1 - Department Werkstoffwissenschaften, Lehrstuhl für Glas und Keramik, Universität Erlangen-Nürnberg. Martensstrasse 5, D-91058 Erlangen, Germany

2 - Institut de Physique du Globe de Paris, 1, rue Jussieu, F- 75005 Paris, France

3 - Université Côte d'Azur, CNRS, Institut de Physique de Nice, UMR 7010, Parc Valrose, Nice, Cedex 2, France

\section{Abstract}

REE-doped glasses have applications in many fields, and for example, Al and $\mathrm{Ce}$ codoping in $\mathrm{SiO}_{2}$ fiber preforms is usually done to attenuate the optical degradation (photodarkening) of e.g. Yb and Tm doped silica optical fibers. In this study, we investigated a $\mathrm{SiO}_{2}$ fiber preform having a gradual increase of the $\mathrm{CeO}_{2}+\mathrm{Al}_{2} \mathrm{O}_{3}$ content from 1.5 to $6.3 \mathrm{~mol} \%$ and a $\mathrm{CeO}_{2} / \mathrm{Al}_{2} \mathrm{O}_{3}$ molar ratio varying from 0.04 to 1.4. Raman and photoluminescence spectroscopies have been used to evaluate changes in the short- and medium-range order both in the cladding and in the core portions, and the evolution of the glass optical properties, respectively. The variations of the excitation and emission bands have been linked to modifications in the vibration bands of the Raman spectra, and in turn, the relationship between optical properties and glass connectivity has been carefully considered. Our results show that there is a strong positive linear relationship between the increase of the Raman bands in the high-frequency range and the red-shift of the excitation maxima. Therefore, the change of $<\mathrm{Ce}$ $\mathrm{O}>$ distances and covalency character influences, in the same way, both the photoluminescence behavior of the core, and the connectivity of the amorphous network.

Keywords: REE, Raman, Photoluminescence, glass structure, cations structural role

\section{Introduction}

Since the 1960s, when the first commercially available silica-based optical fiber was developed, the applications of this material have greatly widened from telecommunication to sensors, to biomedical applications [1,2]. In a recent review, Ballato and coauthors [1] report an overview of the main characteristics of optical fibers, and about the development of new 
materials and processes that will enable the design of advanced optical fibers suited to further uses. Above and beyond the development of new bulk chemistries or of composite materials (e.g. nanoparticles), researcher have first tried to enhance our understanding of $\mathrm{SiO}_{2}$-based optical fibers by studying the occurrence of defects under various conditions, or by investigating the effect of doping on the formation or suppression of defects e.g. [3-5]. Many other studies were focused on the core composition, in order to avoid the clustering of Rare Earth Elements (REE), and enhance REE solubility, e.g. [6,7]. Al and/or P and/or Ce codoping, besides increasing REE solubility, has been recognized as a very effective way to mitigate $\mathrm{Yb}$ - or Tmbased fibers optical degradation (aka photodarkening) [8,9]. For instance, a combination of Al or $\mathrm{P}$, or the codoping of $\mathrm{Al}, \mathrm{P}$ and $\mathrm{Ce}$ is able to reduce the photodarkening of Si-based fibers. This mitigation, in Ce-codoped fibers have been attributed to the coexistence of cerium with two stable oxidation state (trivalent and tetravalent), and the occurrence of two processes: either $\mathrm{Ce}^{3+}$ that by trapping a hole may lose the $4 f$ electron to form $\mathrm{Ce}^{4+}$ species or $\mathrm{Ce}^{4+}$ trapping an electron to form $\mathrm{Ce}^{3+}$ species [8-12]. Significantly fewer studies have been devoted to the understanding of how elements enter into the silica network, and how the different properties of the $\mathrm{SiO}_{2}$ optical fibers are modified e.g. $[6,13]$. Because of the strong link between glass structure and properties, an understanding of the cations speciation would lead not only to the understanding of the mitigation of the photodarkening, but also to the understanding of the glass fibers properties on a broader scale. Indeed, this lack of knowledge hampers the development of new materials and applications. Consequently, we started an investigation of silica optical fiber preforms codoped with cerium and/or aluminum, focusing on the element structural role and glass connectivity. In a recent study, we assessed the role of aluminum in influencing Ce speciation (valence, coordination, bond character) in aluminosilicate glasses and Ce-doped or $\mathrm{Ce} / \mathrm{Al}$ codoped silica fiber preforms, collapsed under different conditions [14]. The addition of aluminum prompts the stabilization of reduced Ce species, and induces variations of the Ce local environment, causing a blue shift of the photoluminescence emission band. Furthermore, it was established a Ce redox ratio limit $\left(\mathrm{Ce}^{3+} / \mathrm{Ce}_{\mathrm{tot}}>0.85 \pm 0.07\right)$ that marks the clear occurrence of additional bands in the UV region. Based on the results, it was evaluated that the photodarkening attenuation is most probably due to to the ability of trivalent Ce to trap hole centers. Since Ce redox ratio and bond covalency change depending on Al concentration/structural role, cerium photoluminescence properties were correlated by considering the glass bulk composition (in terms of optical basicity), and Al average coordination [14]. Despite the remarkable results obtained, codoping at the dilute scale may influence differently the response of the properties. 
In the present study, by using a $\mathrm{SiO}_{2}$ fiber preform having a gradual change of the $\mathrm{Al}_{2} \mathrm{O}_{3} / \mathrm{CeO}_{2}$ molar ratio codoping, we correlate cerium photoluminescence properties to the variations occurring in the glass connectivity, and in turn on the codopant structural role (valence, bond distances, and coordination). Raman spectroscopy was used to identify changes in the short- and medium-range order of cladding and codoped cores, and these results were associated to the variations observed in the luminescence properties, and in turn, to the $\mathrm{Ce}$ species structural environment.

In addition to photodarkening attenuation, the luminescence properties of cerium (and REE in general) are quite important in many other fields, including phosphors, scintillators and generation of fiber gratings [15-19]. Hence, understanding the evolution of cerium (REE) valence and local environment and the effects on the host structure has a key role in the development of new materials and technical applications.

\section{Experimental Methods}

Preform was prepared by the conventional modified chemical vapor deposition (MCVD) technique. In order to obtain a gradual change of the codopant molar ratio along the preform, aluminum and cerium were incorporated with the gradual solution doping technique [20]. Two doping solutions were prepared: solution A contains $1 \mathrm{~mol} / 1$ of $\mathrm{AlCl}_{3}: 6 \mathrm{H}_{2} \mathrm{O}$; in solution $\mathrm{B}, \mathrm{CeCl}_{3}: 6 \mathrm{H}_{2} \mathrm{O}$ and $\mathrm{AlCl}_{3}: 6 \mathrm{H}_{2} \mathrm{O}$ concentrations were 1 and $1 \mathrm{~mol} / \mathrm{l}$, respectively. The pure silica core porous layer was soaked first with solution A. Then, solution A is removed and the solution B is injected in the preform and slowly drained until the bottom (draining time: 20 minutes) to induce a change in cerium concentration. After drying of the solvent, the core layer was sintered down to a dense glass layer in $\mathrm{O}_{2}$ flux. Then, the tube was collapsed under the same flux into a solid rod, referred to as preform, at an elevated temperature higher than 1800 ${ }^{\circ} \mathrm{C}$.

Small disks ( $1 \mathrm{~mm}$ thickness) of the solid rod (9 mm diameter) have been cut at different positions along the preform. Each disk represents a different $\mathrm{CeO}_{2} / \mathrm{Al}_{2} \mathrm{O}_{3}$ molar ratio in the codoped core, starting from the sample cut at $4 \mathrm{~cm}\left(\mathrm{CeO}_{2} / \mathrm{Al}_{2} \mathrm{O}_{3}=0.04\right)$, up to the sample cut at $32 \mathrm{~cm}\left(\mathrm{CeO}_{2} / \mathrm{Al}_{2} \mathrm{O}_{3}=1.4\right)$ as well as a variation of the $\mathrm{CeO}_{2}+\mathrm{Al}_{2} \mathrm{O}_{3}$ content from 1.5 to 6.3 mol\% (see Table 1). The surrounding cladding is composed almost exclusively by $\mathrm{SiO}_{2}(99.98$ - $99.89 \mathrm{~mol} \%$ ), with small impurities of $\mathrm{Al}_{2} \mathrm{O}_{3}$. Disks are labeled according to the distance, and then to the increasing $\mathrm{CeO}_{2} / \mathrm{Al}_{2} \mathrm{O}_{3}$ molar ratio. A schematic drawing (Figure 1) reports sample labels, and codopant molar ratios, whereas the core composition is reported in Table 1. Images and chemical analyses have been obtained by Energy dispersive X-ray (EDX) and scanning 
electron microscope (SEM) analysis at the Institute de Physique du Globe de Paris (France). The SEM-EDX mapping allowed checking the homogeneous distribution of the dopants in the core portions. Photoluminescence spectra of each disk core have been collected with a spectrofluorometer equipped with double monochromators (Czerny-Turner) in excitation and emission (Fluorolog3, Horiba Jobin Yvon), using a $450 \mathrm{~W}$ Xe-lamp as the excitation source (excitation and emission spectral resolution $\leq 1.5 \mathrm{~nm}$ ). Spectra have been normalized to the maximum intensity. Raman spectra have been collected both with laser excitations at $488 \mathrm{~nm}$ and $532 \mathrm{~nm}$ at the Department of Materials Science and Engineering (WW3, FAU ErlangenNürnberg, Germany). The Thermo Scientific Nicolet ${ }^{\mathrm{TM}}$ Almega Raman spectrometer (532nm) coupled with a high-quality Olympus visible microscope (objective 100x), and a highresolution grating (2400 lines/mm) provides a very good spatial and frequency resolution, respectively of $\sim 1 \mu \mathrm{m}$ and $1 \mathrm{~cm}^{-1}$. All spectra have been normalized to the total area, after removal of a polynomial background. Moreover, Raman spectra were also collected with a different excitation line $(488 \mathrm{~nm})$ in order to check the presence of any contribution arising from luminescence centres.

Figure 1: Schematic drawing of the core portion of the $\mathrm{SiO}_{2}$ preform (silica cladding not represented). Each bold number indicates the position where the disks have been cut $(\mathrm{cm})$ along the preform, which also represents samples labeling. Darker color indicates a higher $\mathrm{CeO}_{2}$ content. On top is reported the $\mathrm{CeO}_{2} / \mathrm{Al}_{2} \mathrm{O}_{3}$ molar ratio in the codoped core.

\section{Results and discussion}

$\mathrm{Ce}^{3+}$, contrary to the oxidized $\mathrm{Ce}^{4+}$ species, is optically active and has fluorescence emission that originates from a transition from one (or more) of the $5 d$ levels, to the $2 \mathrm{~F}$ ground state $[7,21,22]$. Trivalent cerium has a [Xe] $4 f^{1}$ ground electronic state, which is split into two sublevels (doublet ${ }^{2} \mathrm{~F}_{5 / 2}$ and ${ }^{2} \mathrm{~F}_{7 / 2}$ ), separated by about $2200 \mathrm{~cm}^{-1}$, and the excited levels $5 d$ lie about $40000 \mathrm{~cm}^{-1}$ above the ground state [22,23]. Despite the well-shielded inner electronic shell, the $f$ - $d$ transitions are strongly dependent on the chemical and structural environment. Hence, both $\mathrm{Ce}^{3+}$ excitation (Ex) and emission (Em) spectra might shift depending on $\mathrm{Ce}$ content, temperature, glass polymerization and connectivity [7,14,22,24,25]. For example, in a previous study on $\mathrm{Na}$ aluminosilicate glasses we observed that both $\mathrm{Ce}^{3+}$ excitation and emission bands shift depending on the $\mathrm{Al} / \mathrm{Na}$ molar ratio, and drastically change for peraluminous compositions [14].

Figure 2 shows the photoluminescence spectra for all codoped core samples. Excitation spectra were collected at the maximum of the emission, and vice versa. By increasing $\mathrm{Ce}$ content, and in turn, the $\mathrm{CeO}_{2} / \mathrm{Al}_{2} \mathrm{O}_{3}$ molar ratio, there is a gradual shift of both Ex and Em 
bands toward lower frequencies. The excitation band is an asymmetric broad band that can be deconvoluted in three contributions, with the first two, respectively at $\sim 35000 \mathrm{~cm}^{-1}(\sim 285 \mathrm{~nm}$; $\left.\mathrm{G}_{3 \mathrm{Ex}}\right)$, and $\sim 32300 \mathrm{~cm}^{-1}\left(\sim 310 \mathrm{~nm} ; \mathrm{G}_{2 \mathrm{Ex}}\right)$, remaining nearly at the same frequency, despite the different compositions (Table 2). On the contrary, the third band is a very small feature centered at $\sim 30900 \mathrm{~cm}^{-1}\left(\sim 324 \mathrm{~nm} ; \mathrm{G}_{1 \mathrm{Ex}}\right)$ in Ce-poor preform (sample 4), which represents only $11 \%$ of the whole excitation band area (Figure 2). By increasing the $\mathrm{CeO}_{2}$ content, this feature gradually shifts toward lower frequencies and increases its intensity, becoming the stronger contribution in sample 32 (representing $\sim 50 \%$ of the whole excitation band). The Ce-rich preform (sample 32) has this contribution centered at $\sim 29600 \mathrm{~cm}^{-1}(\sim 339 \mathrm{~nm})$ (Table 2).

The asymmetric luminescence is related to the allowed electronic transition $5 d \rightarrow 4 f$, and two sublevels of $\mathrm{Ce}^{3+}$ transitions from the $5 d$ to $2 \mathrm{~F}_{7 / 2}$ and $2 \mathrm{~F}_{5 / 2}$ states are clearly discernible (Figure 2). The emission bands have been analyzed and deconvoluted in two Gaussians that are split by $\sim 2300 \mathrm{~cm}^{-1}$ apart, in agreement with the L-S splitting of $\mathrm{Ce}^{3+}$ ions [22,23]. Sample 9 presents the minimum split of $\sim 2180 \mathrm{~cm}^{-1}$ (see Table 2$)$, and has the lowest Stokes shift $(\sim 5100$ $\mathrm{cm}^{-1}$ ). By increasing the Ce content, there is a general decrease of the Em asymmetricity, and an increase of both Stokes shifts and ground level splitting. Additionally, the emission shows a red shift, with the Em maximum moving from $27400 \mathrm{~cm}^{-1}$ to $24000 \mathrm{~cm}^{-1}$ ( 366 and $416 \mathrm{~nm}$, respectively), by increasing Ce content (Figure 2). Band position and results from the bands' deconvolution of both excitation and emission spectra are reported in Table 2.

Figure 2: Normalised excitation (Ex) and emission (Em) spectra for the different samples, and deconvoluted Gaussian bands. By increasing the $\mathrm{CeO}_{2}$ molar content both $\mathrm{Ex}$ and $\mathrm{Em}$ bands show a red shift, and an increase of Stokes shifts and of the ground level splitting. The luminescence properties of sample 4 are different. See text for details.

Absorption bands of Ce ions in glasses, attributed to the $4 f_{1} \rightarrow 5 d_{1}$ transition, have been reported in the wide-ranging region $28500-50000 \mathrm{~cm}^{-1}$, depending on the bulk chemistry. In this region, two broad contributions related to charge transfer (CT) transition of $\mathrm{Ce}^{4+}$ overlap with the $\mathrm{Ce}^{3+}$ ions $4 f_{1} \rightarrow 5 d_{1}$ bands [7,22,26-28]. The position and the intensity of $\mathrm{Ce}^{4+} \mathrm{CT}$ absorption bands change remarkably depending on glass (host) composition $[24,29,30] . \mathrm{Ce}^{3+}$ emission band as well may cover a wide range of frequencies, depending on glass composition, and in particular, the presence of aluminum causes a marked blue shift of the luminescence band in Ce-doped glasses (e.g. [7]), along with a change in the cerium average oxidation state [14]. Based on the previous investigations on the influence of bulk chemistry (optical basicity) and $\mathrm{Al}$ content on Ce redox state [14,31,32], we do not expect a very high amount of oxidized species in the preform cores. Because of the low basicity of the glass (very high amount of 
$\mathrm{SiO}_{2}$ ) and a $\mathrm{CeO}_{2} / \mathrm{Al}_{2} \mathrm{O}_{3}$ molar ratio $>0.1$, we estimate a $\mathrm{Ce}^{3+} / \mathrm{Ce}_{\text {tot }}$ ratio $\leq 0.8$ for all glasses, except for the Ce-poor one (sample 4). The latter has $>98 \mathrm{~mol} \%$ of $\mathrm{SiO}_{2}$, and a $\mathrm{CeO}_{2} / \mathrm{Al}_{2} \mathrm{O}_{3}$ ratio of 0.04 , and an expected $\mathrm{Ce}^{3+} / \mathrm{Ce}_{\text {tot }}$ ratio $\geq 0.9$. In addition, since the excitation bands of samples 32 to 9 are very similar to those previously reported for aluminosilicate and $(\mathrm{Ce}, \mathrm{Al})$ codoped silica fiber preforms [14], we are confident that they should have a similar average estimated $\mathrm{Ce}^{3+} / \mathrm{Ce}_{\text {tot }}$ ratio. In contrast, sample 4 excitation has the two strongest contributions at higher frequencies: In particular, the contribution at $\sim 35700 \mathrm{~cm}^{-1}(\sim 280 \mathrm{~nm})$, has a frequency compatible with the occurrence of band(s) related to charge transfer transitions. In peraluminous silicate glasses and $(\mathrm{Ce}, \mathrm{Al})$ codoped silica fibers this band has been observed to become predominant for high amount of reduced Ce species [14]. Since sample 4 has an expected $\mathrm{Ce}^{3+} / \mathrm{Ce}_{\text {tot }}$ ratio $\geq 0.9$, following optical basicity considerations, we might associate as well the high-frequency band in the excitation signal to trapped hole centers, and in turn, to trivalent cerium that may lose the $4 f$ electron: $\mathrm{Ce}^{3+}+\mathrm{h}^{+}=\mathrm{Ce}^{3++}+\mathrm{e}^{-}$.

In order to exclude any possible contribution from the silica glass, the photoluminescence signals of some of the cladding portions have been measured as well, by using the same experimental conditions used for the codoped cores. It was observed the occurrence of some bands in the outer silica claddings, with visible intensity variations across the portion analyzed. The broad contributions observed have maxima centered at $\sim 27000$ and $\sim 22700 \mathrm{~cm}^{-1}$ (excitation and emission maxima, respectively). These bands may be related to some impurities, and most likely to the occurrence of Si defects in the cladding. The most intense bands observed have been compared to the signals collected in the core (Figure 3). Photoluminescence spectra of the codoped cores have been collected at the maximum of the excitation or of the emission signals, indicated by the vertical black arrows in Figure 3. The signal intensity increases by increasing the Ce molar content, both in the excitation and in the emission. The strongest excitation signal observed in the different cladding (grey solid line) consists of a broad asymmetric band centred at $\sim 370 \mathrm{~nm}$ and a minor contribution at $\sim 300 \mathrm{~nm}$ (orange vertical arrow). Two emission spectra are reported for the cladding, one collected with an excitation wavelength of $300 \mathrm{~nm}$ (orange solid line, a position almost overlapping the maximum of sample 4) and one collected at $350 \mathrm{~nm}$ (grey solid line). Even if the emission of Ce-doped samples ( 9 to 32) overlaps the one of the cladding, the contribution that the cladding might provide is at least 6 times smaller and shifted at lower frequencies. The Ex signal of the cladding is partially overlapping the cores Ex bands, and may contribute to the signal only on the tail at lower frequencies, thus without influencing the three main contributions (Figure 2). Therefore, the influence of the silica cladding on Ce bands is very limited. 


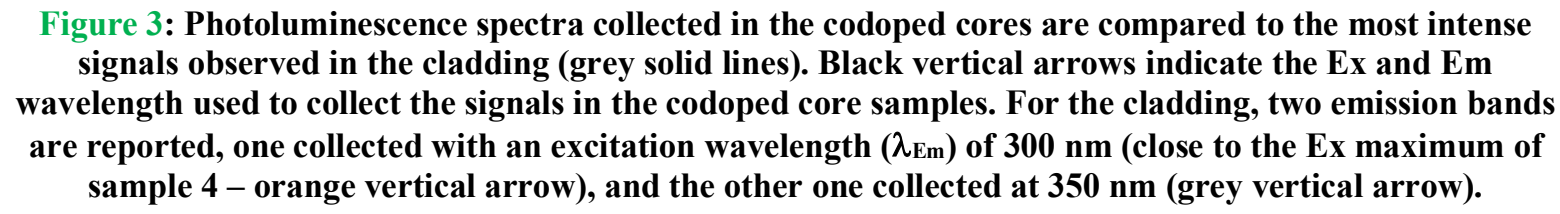

In order to better understand the frequency shifts and the photoluminescence evolution depending on the Ce content, we have taken into account the possible occurrence of different cerium populations. Figure 4 shows the excitation spectra of samples 4 and 32 (black solid lines), and the three Gaussian functions used for signal deconvolution (dotted lines). Emission spectra have been collected for different excitation wavelengths (vertical arrows) for both samples. When the excitation increases from 280 to $335 \mathrm{~nm}\left(\sim 35700\right.$ to $\sim 29900 \mathrm{~cm}^{-1}$, respectively) the emission of sample 32 barely shifts $\left(\sim 620 \mathrm{~cm}^{-1}\right)$, and the two Emission bands have a very similar shape. Therefore, it is reasonable to consider that we are exciting the same electronic level. On the contrary, in the Ce-poor glass (sample 4) the Em maximum drastically shifts (up to $\sim 3900 \mathrm{~cm}^{-1}$ ) for the same excitation wavelengths reported above. Furthermore, besides the change of the Em maximum depending on the excitation wavelength, there is also a variation of band symmetry (Figure 4). In the case of crystalline materials, it has been reported that the distortion of $\mathrm{Ce}^{3+}$ sites affects the crystal field splitting of the $5 d$ configuration, and that the occurrence of vacancies might contribute in changing Ce charge distribution. Consequently, both would lead to red shift emission and changes in band symmetry [33-35]. In case of amorphous materials, stronger crystal field splitting would lower the energy level of the $5 d$ configuration. Moreover, the increase of bond covalency character as well might affect the $5 d$ orbital. Hence, both covalency and crystal field increases induce a red shift. Following these considerations, we might expect that the different emission signals of sample 4 derive from the distribution of $\mathrm{Ce}$ in different sites, and in turn, to the different chemical environments surrounding $\mathrm{Ce}^{3+}$ ions (i.e. $<\mathrm{Ce}-\mathrm{O}>$ distances and bond covalency). In particular, we could consider that the shorter wavelength emitting site is less covalent in nature, whereas the longer wavelength emitting site is less ionic. The increase of Ce content induces a red shift of the excitation because the longer wavelength emitting site becomes predominant.

Because of the very low doping level of Ce in sample 4, it is required to consider the 273 combination of other effects, such as the occurrence of i) trapped hole centers-related 274 transitions, with $\mathrm{Ce}^{3++}$ ions having different energy states, and ii) the presence of part of the $275 \mathrm{Ce}^{3+}$ ions localized around point defects. The latter hypothesis might explain why the observed photoluminescence signals are so different. 

different excitation wavelengths marked by the vertical arrows.

\section{3}

The Raman spectra of silicate glasses can be divided in different major regions, and we will consider two of them: the high and the low-frequency regions. The low-wavenumber region from $\sim 350$ to $650 \mathrm{~cm}^{-1}$, gives information on the T-O-T rocking, bending mode and ring distributions (see [36] and references therein). The high-wavenumber portion extending from $\sim 860$ to $1300 \mathrm{~cm}^{-1}$ (also referred as $Q$-range) contains stretching motions of tetrahedral cations $\mathrm{T}$ (e.g. $\mathrm{T}=\mathrm{Si}^{4+}, \mathrm{Al}^{3+}$ ) [36]. The short-range order of silicate glasses can be described through the abundance of the $Q^{n}$ species, where $n$ is the number of bridging oxygen atoms (BO) and $Q$ represents the four-fold coordinated cation (i.e. fully polymerized $=Q^{4}$ ). A fully polymerized $\mathrm{SiO}_{2}$ glass network has only weak bands in the frequency range $\sim 950-1300 \mathrm{~cm}^{-1}$, whereas it has a strong asymmetric band in the low-frequency region $\left(350-500 \mathrm{~cm}^{-1}\right)$. Moreover, highly polymerized glasses have two well-pronounced peaks, usually referred to as defect lines, $D_{l}$ ( $\left.490 \mathrm{~cm}^{-1}\right)$ and $D_{2}\left(\sim 600 \mathrm{~cm}^{-1}\right)$, associated, respectively, with the breathing modes of $(\mathrm{SiO})_{4}-$ and $(\mathrm{SiO})_{3}$-rings $[37,38]$. In general, by increasing the number of non-bridging oxygen (NBO), the main band in the low-frequency region decreases in intensity and shifts to higher wavenumbers, whilst the $Q$-range shifts toward lower frequencies and increases its intensity because other bands (related to other $Q$ species, such as $Q^{3}, Q^{2}$ ) appear in the $850-1300 \mathrm{~cm}^{-1}$ portion ([36] and references therein). $\mathrm{SiO}_{2}$ glass vibrations in the $Q$-range can be deconvoluted with three main contributions that represent different types of stretching vibration of the $\mathrm{SiO}_{4}$ tetrahedra [39-42], and here we use the same terminology adopted in our previous work (see [14] and reference therein). Indeed, to describe the vibration of the $\mathrm{SiO}_{4}$ tetrahedra in silica glass we use $Q^{4, I}$, and $Q^{4, I I}$ species (at frequencies higher than $1100 \mathrm{~cm}^{-1}$ ), and the $T_{2}$ stretching mode at $\sim 1050 \mathrm{~cm}^{-1}$ (the latter related to two oxygen atoms that move closer to the central $\mathrm{T}$ atom, while the other two oxygens of $\mathrm{TO}_{4}$ tetrahedra move away) [43].

The cladding portion of all samples is nearly completely composed of $\mathrm{SiO}_{2}\left(\mathrm{Al}_{2} \mathrm{O}_{3}\right.$ impurities $\leq 0.13 \mathrm{~mol} \%$ ), thus the Raman spectrum of a pure $\mathrm{SiO}_{2}$ glass (QSIL $($ ), collected with the same experimental conditions, has been used as reference (dashed line in Figure 5A). In the cladding portions analyzed, Raman spectra show some small variations compared to the reference $\mathrm{SiO}_{2}$, mainly on the intensity of the defect lines, and on the relative intensity of the bands in the $Q$-range. In $\mathrm{SiO}_{2}$-rich amorphous materials having less than 4 mol\% $\mathrm{Al}_{2} \mathrm{O}_{3}, \mathrm{NMR}$ 
312 data indicates the occurrence of $\mathrm{Al}^{3+}$ mostly 4-fold coordinated $\left({ }^{[4]} \mathrm{Al}^{3+}\right)$ with small contributions from distorted ${ }^{[6]} \mathrm{Al}^{3+}$ (6-fold coordinated) [44]. Al, as network former, mainly enters the more distorted $Q^{4, I I}$ sites causing an intensity increase and a small negative shift of this band $[14,45]$. These considerations fit well with the signal collected in the cladding, and thus, we can relate the small variations observed among the different claddings to the inclusion of $\mathrm{Al}^{3+}$ in the tetrahedral sites, which induces different average $<\mathrm{T}-\mathrm{O}>$ distances and small changes in the ring statistic (insets in Figure 5A). The mathematical average of the seven different claddings (hereafter called $\overline{C l a d}$ ) was done in order to have a reference spectrum that takes into account the chemical variability found in the outer cladding. The $\overline{C l a d}$ spectrum is reported in Figure 5B (solid black line) and compared to the spectra collected in the core areas.

In the core portions analyzed, the $(\mathrm{Ce}, \mathrm{Al})$ codoping induces much more visible changes in the glass network, both in the short-and medium-range order. At low frequencies, the main T-O-T band and the defect bands decrease in intensity and the latter become broader, compared to $\mathrm{SiO}_{2}$ and $\overline{C l a d}$ (Figure $\left.5 \mathrm{~B}\right)$. Moreover, there is a small shift $\left(\sim 2-3 \mathrm{~cm}^{-1}\right)$ toward higher frequencies of the maximum of the low-frequency region. These changes indicate a lower quantity of smaller $(\mathrm{SiO})_{4}-$ and $(\mathrm{SiO})_{3}$-rings with the increase of the doping, and the shift to higher wavenumbers of the Main Band suggests a small decrease of the ring intertetrahedral angles T-O-T. The strongest variations observed in the cores are in the $860-1300 \mathrm{~cm}^{-1}$ frequency region, where new contributions systematically rises (between $\sim 860$ and $1050 \mathrm{~cm}^{-1}$ ) by increasing the $\mathrm{CeO}_{2}$ content (inset Figure 5B).

Figure 5: Raman spectra collected in the cladding (A), and in the codoped core (B) of the different disks. A) The Raman spectrum of pure $\mathrm{SiO}_{2}$ glass (dashed black line) is compared to signals from the cladding portions .B) An average spectra of all claddings $(\overline{C l a d}$, black solid line) is reported as reference and compared to the core signals. Insets provide a magnification of the $D_{2}$ defect line, and of the $Q$-range.

In order to evaluate the modifications occurring in the glass structure upon incorporation of $\mathrm{Ce}$ and $\mathrm{Al}$ oxides, and the influence of the different Ce contents, we studied in detail the high-frequency region by means of two approaches. The first one is a subtractive method where the signal of the cladding has been subtracted to the signal collected in the core, and the difference spectrum has been deconvoluted by mathematical functions. The second approach involves the more classical deconvolution of the whole high-frequency portion.

In order to separate the contributions to the Raman spectra due only to the $\mathrm{Al} / \mathrm{Ce}$ codoping, the signal collected into the cladding has been subtracted to the one collected in the core region, for each sample. The resulting difference spectra highlights the distinct portions 
where the vibrational bands are affected by the incorporation of $\mathrm{Al}_{2} \mathrm{O}_{3}$ and $\mathrm{CeO}_{2}$ (Figure $6 \mathrm{~A}$ ). In the low-frequency region, the relative intensity of the defect lines changes depending on the amount of codoping. Furthermore, the shift of the main band at $\sim 434 \mathrm{~cm}^{-1}$ is evident (Figure 6B). In the high-frequency portion, the contribution in the $Q$-range, $860-1050 \mathrm{~cm}^{-1}$, strongly increases by increasing the $\mathrm{Ce}$ and $\mathrm{Al}$ content (Figure 6C). The modifications observed in the asymmetric band centred at $\sim 800 \mathrm{~cm}^{-1}$ will not be discussed here, preferring to focus on changes in the $Q$-range. Figure 6D reports an example of the subtractive method used here. The cladding and core spectra collected for sample 32 are shown in Figure 6D, along with the difference spectrum obtained (symbols). The latter has been fitted, and four contributions can be distinguished for high codoping: two well defined bands that are related to the two main peaks (named $\mathrm{P}_{2}$ and $\mathrm{P}_{3}$ ), and two smaller side bands associated with the shoulder observed for each of the main peaks ( $\mathrm{P}_{1}$ and $\mathrm{P}_{4}$, respectively at lower and higher frequencies in Figure 6D). The difference spectrum of sample 4 presents a single contribution centred at $1120.2(2) \mathrm{cm}^{-1}$ (Figure 6E). The difference spectrum is well fit with a Lorentzian function with a full-width half-maximum FWHM $=45.5(3) \mathrm{cm}^{-1}$ (the use of a Gaussian for this sample would imply the use of other two side bands, and we prefer to use the minimum number of bands to achieve a satisfactory fit). The difference spectrum obtained between pure $\mathrm{SiO}_{2}$ and a reference glass having $98.8 \mathrm{~mol} \% \mathrm{SiO}_{2}$ and $1.2 \mathrm{~mol}_{0} \mathrm{Al}_{2} \mathrm{O}_{3}$ indicates a residual contribution with a nearly identical shape and position $\left(1120.9(10) \mathrm{cm}^{-1}\right.$; unpublished data). Since sample 4 core has 1.5 mol\% of $\mathrm{Al}_{2} \mathrm{O}_{3}$, and only $0.05 \mathrm{~mol} \%$ of $\mathrm{CeO}_{2}$ we can affirm with confidence that this contribution is only due to the $\mathrm{Al}^{3+}$ cations entering the tetrahedral sites. By increasing the $\mathrm{Ce}$ content to $\sim 1 \mathrm{~mol} \%$, another main contribution appears, which represents $50 \%$ of the whole area. Indeed, sample 9 difference spectrum requires two Gaussian bands, named $\mathrm{P}_{2}$ and $\mathrm{P}_{3}$, respectively centered at $988.5(2) \mathrm{cm}^{-1}$ and $1118.7(4) \mathrm{cm}^{-1}$ to fit the two dominant contributions (see Figure 6E). Additionally, a small shoulder is visible in the high-frequency portion $\left(\mathrm{P}_{4}\right.$ band). Further addition of $\mathrm{CeO}_{2}$ induces the increase of the $\mathrm{P}_{2}$ band, and the appearance of the shoulder at lower frequencies $\left(\mathrm{P}_{1}\right)$. Thus, these two bands $\left(\mathrm{P}_{1}+\mathrm{P}_{2}\right)$ contribute to more than $60 \%$ of the total difference spectra (see Table 3).

The subtractive method here used allows underlining that the main variations in the $Q$ range are related to the appearance of the $P_{1}$ and $P_{2}$ contributions (respectively at $\sim 917$ and $\sim$ $985 \mathrm{~cm}^{-1}$ ) and their rise by increasing the $\mathrm{CeO}_{2}$ and $\mathrm{Al}_{2} \mathrm{O}_{3}$ content. Based on this data analysis, we propose the following assignment for the two main contributions: $\mathrm{P}_{3}$ to Al-O stretching modes and $\mathrm{P}_{2}$ to the presence of cerium ions. 
Figure 6: A-C) Raman spectra collected in the core region and the subtracted spectra obtained by the difference between core and cladding of the same sample. Magnifications of the defect lines and of the $Q$ range are reported, respectively, in panel $B$ and $C$. In $A$, a Cladding spectrum is reported as reference in black. D) Example of the subtractive method used. The Raman signal of each cladding has been subtracted to the one collected into the core region. The difference spectrum obtained has been deconvoluted with mathematical functions, and based on their positions we use the labels $P_{1}, P_{2}, P_{3}$ and $P_{4}$. E) Stacked difference spectra and position of the mathematical functions for some of the samples.

The second method used to study the variations occurring in the Raman signals involves the more classical fit of the whole high-frequency region. The deconvolution has been done for all samples, both in the cladding and codoped core portions. As a reference, the analysis of the Raman signals of the $\mathrm{SiO}_{2}$ glass and of the average cladding $\overline{C l a d}$ was done as well in the range 950-1300 $\mathrm{cm}^{-1}$. As reported above, pure $\mathrm{SiO}_{2}$ glass weak bands in the $Q$-range can be deconvoluted with three main contributions related to $Q$ species with four bridging oxygens. In the cladding portions, these three bands are assigned to $Q^{4, I}, Q^{4, I I}$ and $T_{2}$ stretching modes (see Figure 7). A small negative frequency shifts of the $Q^{4, I I}$ species is probably due to $\mathrm{Al}^{3+}$ cations entering the tetrahedral sites. The results of the fit of $\mathrm{SiO}_{2}$ and of the average cladding $(\overline{C l a d})$ $Q$-range Raman signals are reported in Table 4. In the codoped core, besides these three main contributions, other two bands appear in the lower part of the $Q$ envelope $\left(<1050 \mathrm{~cm}^{-1}\right)$, and increase in intensity by increasing the (Ce, Al) doping (see Figure 7). These two contributions below $1050 \mathrm{~cm}^{-1}$ are not related to electronic transitions (luminescence) because they have the same intensities and Raman shift position even when collected with a different excitation line. In order to give stable fits, the full-width half maximum (FWHM) of the Gaussian functions should be constrained below $60 \mathrm{~cm}^{-1}$ [46], thus, a further contribution between $1090-1110 \mathrm{~cm}^{-}$ ${ }^{1}$ should be added. This supplementary band would take into account the occurrence of $Q^{3}$ species possibly due to both $\mathrm{Ce}$ ions and higher coordinated $\mathrm{Al}^{3+}$ species acting as network modifiers. However, due to pure fit stability, we decided to avoid including this further contribution. Therefore, only five Gaussian functions were used to deconvoluting core Raman spectra: the three related to $\mathrm{TO}_{4}$ tetrahedra (hereafter called $\mathrm{G}_{1}$ to $\mathrm{G}_{3}$ ) and two additional contributions at lower frequencies (hereafter called $\mathrm{G}_{4}$ and $\mathrm{G}_{5}$ ).

By increasing the codoping, the bands $G_{1}$ to $G_{3}$ show a minor increased intensity compared to the cladding, and a shift of the component at $\sim 1150 \mathrm{~cm}^{-1}\left(\mathrm{G}_{2}\right)$. On the other hand, the two additional bands at lower frequencies $\left(\mathrm{G}_{4}, \mathrm{G}_{5}\right)$ strongly increase by increasing the cerium content. Thus, particular attention will be given to the frequency and intensity evolution of the bands at $\sim 925 \mathrm{~cm}^{-1}\left(\mathrm{G}^{4}\right)$ and $\sim 980 \mathrm{~cm}^{-1}\left(\mathrm{G}^{5}\right)$. This increase in $\mathrm{G}_{4}$ and $\mathrm{G}_{5}$ intensities leads the whole $Q$ envelope to move toward lower frequencies. To represent this tendency we used the center of mass $\mathrm{C}$ (or centroid) of the analyzed range, calculated as (see Table 4): 


$$
C=\frac{\left(G^{1} * A_{G^{1}}\right)+\left(G^{2} * A_{G^{2}}\right)+\left(G^{3} * A_{G^{3}}\right)+\left(G^{4} * A_{G^{4}}\right)+\left(G^{5} * A_{G^{5}}\right)}{A_{\text {tot }}}
$$

420

421

422

423

424

425

426

427

428

429

430

431

432

433

434

435

436

437

438

439

440

441

442

443

444

445

446

447

448

449

450

451

452

(where $\mathrm{A}_{\text {tot }}$ is the total area of the $Q$-range; see Table 4) resulting in $\sim-60 \mathrm{~cm}^{-1}$ shift of the highfrequency band by increasing the $\mathrm{Ce}, \mathrm{Al}$ codoping from 1.5 to $6.3 \mathrm{~mol} \%$. As reference, the center of mass of pure $\mathrm{SiO}_{2}$ has been estimated at $\sim 1119.7 \mathrm{~cm}^{-1}$, whereas the one related to the average cladding signal is $\sim 1116 \mathrm{~cm}^{-1}$ (see Table 4 ). Sample 32 core has a very high amount of $\mathrm{CeO}_{2}(\sim 3.7 \mathrm{~mol} \%)$ and does not follow the trend observed for the other codoped cores. A possible explanation takes account of the clustering taking place because of the high Ce content.

This deconvolution method, as the subtractive one, highlights that the higher doping induces strong changes in the glass topology, and the rise of the bands in the lower frequency of the $Q$-range is associated to the higher content of Ce ions. Despite the increase of codopant amount in the core (and in turn, the decrease of silica), it seems that there is not a strong depolymerization since the Raman Main Band was only slightly affected. A decrease of $Q^{4}$ species is anyway restricted since $\mathrm{Al}^{3+}$ ions tend to enter preferentially the $Q^{4, I I}$ site. The main role of cerium ions is then uncertain. It could be charge-compensator of $\mathrm{Al}^{3+}$ ions, and/or directly connected to the tetrahedral network. Then, the contributions $\mathrm{G}_{4}$ and $\mathrm{G}_{5}$ could be associated to a weakening of the stretching of the bond Si-O when Ce is nearby, by analogy of recent assignments done by Nesbitt et al. [47].

\section{Figure 7: Details of the Raman spectra and deconvolution of the high-frequency regions of some of the samples investigated. In the codoped core, for $\mathrm{CeO}_{2}$ contents $\geq 1 \mathrm{~mol} \%$, two additional vibrations rise, respectively at $\sim 916 \mathrm{~cm}^{-1}$ and $\sim 970 \mathrm{~cm}^{-1}$. The chemical compositions of both cladding and core are reported for sake of clarity (as mol\% oxide).}

In order to assess and link structural changes to macroscopic properties in the codoped cores, we correlated the variations observed in the glass connectivity to the cerium photoluminescence properties, by taking into account the center of mass and the integrated areas of the deconvoluted bands in the $Q$-range, and the frequency position of Excitation and Emission signals.

By changing the codopant amount in the core portions, it is possible to observe a common trend for all the parameters taken into account, related both to the glass structure and to the optical properties. The decrease of the $Q$-range center of mass is very well correlated with the red shift of both Excitation and Emission maxima. Indeed, by increasing the codoping, the center of mass of the $Q$-range drop, similar to the drop observed in the photoluminescence maxima (Figure 8A). Furthermore, we can observe that sample 4 has the highest value of the 
453

454

455

456

457

458

459

460

461

462

463

464

465

466

467

468

469

470

471

472

473

474

475

476

477

478

479

480

481

482

483

484

485

486

487

488

$Q$-range center of mass, which in turn corresponds to the highest values of Ex and Em. Sample 4 presents the most different photoluminescence properties and its $\mathrm{C}$ value is very close to the one calculated for the average cladding. A plausible explanation could be that a very low doping level of $\mathrm{Ce}^{3+}$ ions induces these species to associate not to the aluminosilicate network but to dangling point defects. Instead, when in higher amounts $\mathrm{Ce}$ ions tend to associate to the aluminosilicate network before reaching the limit of cerium clusters formation. This could be appreciated by looking at the increase of the integrated area of the bands in the lower portion of the $Q$-range (Figure $8 \mathrm{~B}$ ), and especially to the practically linear correlation between the sum of the integrated area of the $\mathrm{P}_{1}$ and $\mathrm{P}_{2}$ bands and the frequency of the excitation maxima (Adjusted Coefficient of Determination $\mathrm{R}^{2}=99.92$ ):

$\mathrm{y}(\mathrm{x})=(-34.5 \pm 2.6) * \mathrm{x}+32772 \pm 202$

This positive relationship means that the change of $<\mathrm{Ce}-\mathrm{O}>$ species covalency character influences, in the same way, both the photoluminescence behavior of the core, and the connectivity of the amorphous network.

The correlation observed between glass short-range order and optical properties endorses that Ce species are strongly connected to the glass network, and the small changes in the medium-range order supports the conclusion that $\mathrm{Ce}^{3+}$ ions partially act as chargecompensator to neighboring $\mathrm{Al}$ polyhedral $\left(\mathrm{AlO}_{4}^{-}, \mathrm{AlO}_{5}{ }^{3-}\right)$. Consequently, $\langle\mathrm{Ce}-\mathrm{O}\rangle$ connectivity changes depending on $\mathrm{Al}$ coordination/content, in agreement with previous experimental and molecular dynamic studies $[14,48]$ and references therein.

\footnotetext{
Figure 8: Correlations between parameters from Raman data analysis and Photoluminescence studies of the codoped cores. A) the Raman center of mass C vs. the Emission (Em) and Excitation (Ex) maxima. B) the frequency Excitation maxima are related to the sum of the integrated areas of the contributions $P_{1}$ and $\mathbf{P}_{2}$, obtained following the subtractive method. The latter shows a nearly perfect linear correlation (Adjusted $R^{2}=$ 99.92).
}

\section{Conclusions}

We investigated a series of silica preforms having different codopant contents in the core, and variations of the $\mathrm{CeO}_{2} / \mathrm{Al}_{2} \mathrm{O}_{3}$ molar ratios from 0.04 to 1.4. Raman spectroscopy has been used to evaluate changes in glass connectivity and modifications in the short- and mediumrange order both in the cladding and in the core portions. Photoluminescence studies of the codoped cores allowed evaluating the evolution of the glass optical properties.

This work allowed determining a correlation between glass topology and optical properties and to better understand the short-range order variations depending on the silica fiber preform codopant ratios. In particular, we observed that: 


\section{1}

502

503

504

505

506

507

508

509

510

511

- by increasing the $\mathrm{CeO}_{2}-\mathrm{Al}_{2} \mathrm{O}_{3}$ content, there is a red shift of both excitation and emission spectra, and at the same time, a clear shift toward lower frequencies of the Raman $Q-$ range;

- very low doping level of $\mathrm{Ce}^{3+}$ ions $(0.05 \mathrm{~mol} \%)$ probably induces these species to associate not to the tetrahedra network but to point defects;

- when in higher amounts Ce ions behave differently, and the positive correlation between glass short-range order and optical properties endorses that Ce species are strongly associated to the aluminosilicate glass network;

- the change of $\langle\mathrm{Ce}-\mathrm{O}\rangle$ bonding character influences, in the same way, both the photoluminescence behavior of the core, and the connectivity of the amorphous network.

The combined use of photoluminescence and Raman spectroscopy enabled discriminating the distinct influence of the two codopants depending on the $\mathrm{CeO}_{2}-\mathrm{Al}_{2} \mathrm{O}_{3}$ content. These results will allow to better design the codopant ratios needed to avoid photodarkening of silica fiber, but also to shed some light on the mechanisms involved in the attenuation of this unwanted optical degradation. Besides application in optical fibers, the understanding of the relationship between macro and micro-scale properties is a necessary step in the way of developing material with ad hoc properties.

\section{Acknowledgment:}

SEM-EDS analyses were supported by IPGP multidisciplinary program PARI, and by Region île-de-France SESAME Grant no. 12015908. 


\section{References}

[1] J. Ballato, H. Ebendorff-Heidepriem, J. Zhao, L. Petit, J. Troles, Glass and Process Development for the Next Generation of Optical Fibers: A Review, Fibers. 5 (2017) 11. https://doi.org/10.3390/fib5010011.

[2] P.D. Dragic, M. Cavillon, J. Ballato, Materials for optical fiber lasers: A review, Appl. Phys. Rev. 5 (2018). https://doi.org/10.1063/1.5048410.

[3] D.L. Griscom, Nature Of Defects And Defect Generation In Optical Glasses, in: Radiat. Eff. Opt. Mater., SPIE, 1985: p. 38. https://doi.org/10.1117/12.975358.

[4] S. Girard, A. Alessi, N. Richard, L. Martin-Samos, V. De Michele, L. Giacomazzi, S. Agnello, D. Di Francesca, A. Morana, B. Winkler, I. Reghioua, P. Paillet, M. Cannas, T. Robin, A. Boukenter, Y. Ouerdane, Overview of radiation induced point defects in silica-based optical fibers, Rev. Phys. 4 (2019) 100032. https://doi.org/10.1016/j.revip.2019.100032.

[5] D.L. Griscom, A Minireview of the Natures of Radiation-Induced Point Defects in Pure and Doped Silica Glasses and Their Visible/Near-IR Absorption Bands, with Emphasis on Self-Trapped Holes and How They Can Be Controlled, Phys. Res. Int. 2013 (2013) 379041. https://doi.org/10.1155/2013/379041.

[6] K. Arai, H. Namikawa, K. Kumata, T. Honda, Y. Ishii, T. Handa, Aluminum or phosphorus co-doping effects on the fluorescence and structural properties of neodymium-doped silica glass, J. Appl. Phys. 59 (1986) 3430-3436. https://doi.org/10.1063/1.336810.

[7] Y. Ishii, K. Arai, H. Namikawa, M. Tanaka, A. Negishi, T. Handa, Preparation of Cerium-Activated Silica Glasses: Phosphorus and Aluminum Codoping Effects on Absorption and Fluorescence Properties, J. Am. Ceram. Soc. 70 (1987) 72-77.

[8] C. Shao, W. Xu, N. Ollier, M. Guzik, G. Boulon, Suppression mechanism of radiationinduced darkening by $\mathrm{Ce}$ doping in $\mathrm{Al} / \mathrm{Yb} / \mathrm{Ce}$-doped silica glasses: Evidence from optical spectroscopy, EPR and XPS analyses, J. Appl. Phys. 120 (2016) 153101. https://doi.org/10.1063/1.4964878.

[9] J.-F. Lupi, M. Vermillac, W. Blanc, F. Mady, M. Benabdesselam, B. Dussardier, D.R. Neuville, Steady photodarkening of thulium alumino-silicate fibers pumped at $107 \mu \mathrm{m}$ : quantitative effect of lanthanum, cerium, and thulium, Opt. Lett. 41 (2016) 2771. https://doi.org/10.1364/OL.41.002771.

[10] M. Engholm, P. Jelger, F. Laurell, L. Norin, Improved photodarkening resistivity in ytterbium-doped fiber lasers by cerium codoping., Opt. Lett. 34 (2009) 1285-1287. https://doi.org/10.1364/OL.34.001285.

[11] S. Jetschke, S. Unger, A. Schwuchow, M. Leich, J. Kirchhof, Efficient Yb laser fibers with low photodarkening by optimization of the core composition, Opt. Express. 16 (2008) 15540. https://doi.org/10.1364/OE.16.015540.

[12] S. Jetschke, S. Unger, M. Leich, J. Kirchhof, Photodarkening kinetics as a function of $\mathrm{Yb}$ concentration and the role of Al codoping, Appl. Opt. 51 (2012) 7758. https://doi.org/10.1364/ao.51.007758.

[13] S. Sen, J.F. Stebbins, Structural role of Nd3+ and Al3 + cations in $\mathrm{SiO} 2$ glass: a 29Si MAS-NMR spin-lattice relaxation, 27Al NMR and EPR study, J. Non. Cryst. Solids. 188 (1995) 54-62. https://doi.org/10.1016/0022-3093(95)00099-2.

[14] M.R. Cicconi, D.R. Neuville, W. Blanc, J.-F. Lupi, M. Vermillac, D. de Ligny, Cerium/aluminum correlation in aluminosilicate glasses and optical silica fiber preforms, J. Non. Cryst. Solids. 475 (2017) 85-95. https://doi.org/10.1016/j.jnoncrysol.2017.08.035.

[15] N. Chiodini, G. Brambilla, A. Vedda, D. Di Martino, M. Fasoli, A. Lauria, M. Redaelli, E. Rosetta, SiO2-based scintillating fibers for X-ray detection, in: Hard X-Ray GammaRay Detect. Phys. V, 2004: pp. 298-305. 
[16] M. Bettinelli, G. Ingletto, P. Polato, G. Pozza, G. Zanella, Optical spectroscopy of $\mathrm{Ce} 3+$, Tb3+ and Eu3+ in new scintillating glasses, Phys. Chem. Glas. 37 (1996) 4-8.

[17] L. Dong, P.J. Wells, D.P. Hand, D.N. Payne, Photosensitivity in Ce`3+-doped optical fibers, J. Opt. Soc. Am. B. 10 (1993) 89. https://doi.org/10.1364/josab.10.000089.

[18] W.W. Morey, G.A. Ball, G. Meltz, Photoinduced Bragg Gratings in Optical Fibers, Opt. Photonics News. 5 (1994) 8. https://doi.org/10.1364/OPN.5.2.000008.

[19] G. Blasse, a. Bril, Investigation of Some Ce3+-Activated Phosphors, J. Chem. Phys. 47 (1967) 5139-5145. https://doi.org/doi:10.1063/1.1701771.

[20] J.-F. Lupi, M. Vermillac, S. Trzesien, M. Ude, W. Blanc, B. Dussardier, Gradual-Time Solution Doping for the Fabrication of Longitudinally Varying Optical Fibres, J. Light. Technol. Vol. 36, Issue 10, Pp. 1786-1791. 36 (2018) 1786-1791.

[21] G.K. Das Mohapatra, A spectroscopic study of cerium in lithium-alumino-borate glass, Mater. Lett. 35 (1998) 120-125. https://doi.org/10.1016/S0167-577X(97)002322.

[22] R. Reisfeld, H. Minti, a. Patra, D. Ganguli, M. Gaft, Spectroscopic properties of cerium in glasses and their comparison with crystals, Spectrochim. Acta Part A Mol. Biomol. Spectrosc. 54 (1998) 2143-2150. https://doi.org/10.1016/S13861425(98)00131-0.

[23] M. Fasoli, A. Vedda, A. Lauria, F. Moretti, E. Rizzelli, N. Chiodini, F. Meinardi, M. Nikl, Effect of reducing sintering atmosphere on Ce-doped sol-gel silica glasses, J. Non. Cryst. Solids. 355 (2009) 1140-1144. https://doi.org/10.1016/j.jnoncrysol.2009.01.043.

[24] A. Paul, M. Mulholland, M.S. Zaman, Ultraviolet absorption of cerium(III) and cerium(IV) in some simple glasses, J. Mater. Sci. 11 (1976) 2082-2086. https://doi.org/10.1007/PL00020336.

[25] A. Herrmann, H.A. Othman, A.A. Assadi, M. Tiegel, S. Kuhn, C. Rüssel, Spectroscopic properties of cerium-doped aluminosilicate glasses, Opt. Mater. Express. 5 (2015) 720. https://doi.org/10.1364/OME.5.000720.

[26] R. Reisfeld, A. Patra, G. Panczer, M. Gaft, Spectroscopic properties of cerium in solgel glasses, Opt. Mater. (Amst). 13 (1999) 81-88. https://doi.org/10.1016/S09253467(99)00015-4.

[27] M.L. Brandily-Anne, J. Lumeau, L. Glebova, L.B. Glebov, Specific absorption spectra of cerium in multicomponent silicate glasses, in: J. Non. Cryst. Solids, 2010: pp. 23372343. https://doi.org/10.1016/j.jnoncrysol.2010.02.020.

[28] H. Ebendorff-Heidepriem, D. Ehrt, Formation and UV absorption of cerium, europium and terbium ions in different valencies in glasses, Opt. Mater. (Amst). 15 (2000) 7-25. https://doi.org/10.1016/S0925-3467(00)00018-5.

[29] J.A. Duffy, G.O. Kyd, Ultraviolet absorption and fluorescence spectra of cerium and the effect of glass composition, Phys. Chem. Glas. 37 (1996) 45-48.

[30] J. Bei, G. Qian, X. Liang, S. Yuan, Y. Yang, Optical properties of Ce 3+-doped oxide glasses and correlations with optical basicity, Mater. Res. Bull. (2007).

[31] F.G.K. Baucke, J.A. Duffy, Redox reactions between cations of different polyvalent elements in glass melts. An optical basicity study, Phys. Chem. Glas. 34 (1993) 158163.

[32] A. Paul, R.W. Douglas, Cerous-ceric equilibrium in binary alkali borate and alkali silicate glasses, Phys. Chem. Glas. 6 (1965) 212-215.

[33] P. Dorenbos, 5d-level energies of Ce 3+ and the crystalline environment., Phys. Rev. B. 62 (2000) 640-649. https://doi.org/10.1103/PhysRevB.62.15640.

[34] F. Wang, W. Wang, L. Zhang, J. Zheng, Y. Jin, J. Zhang, Luminescence properties and its red shift of blue-emitting phosphor Na3YSi3O9 :Ce3+ for UV LED, RSC Adv. 7 (2017) 27422-27430. https://doi.org/10.1039/C7RA03813E. 
640

641

642

643

644

645

646

647

648

649

650

651

652

653

654

655

656

657

658

[35] P. Dorenbos, Ce3+ 5d-centroid shift and vacuum referred 4f-electron binding energies of all lanthanide impurities in 150 different compounds, J. Lumin. 135 (2013) 93-104. https://doi.org/10.1016/j.jlumin.2012.09.034.

[36] D.R. Neuville, D. de Ligny, G.S. Henderson, Advances in Raman Spectroscopy Applied to Earth and Material Sciences, 2014. https://doi.org/10.2138/rmg.2013.78.13.

[37] S.K. Sharma, J.F. Mammone, M.F. Nicol, Raman investigation of ring configurations in vitreous silica, Nature. 292 (1981) 140-141. https://doi.org/10.1038/292140a0.

[38] A. Pasquarello, R. Car, Identification of Raman Defect Lines as Signatures of Ring Structures in Vitreous Silica, Phys. Rev. Lett. 80 (1998) 5145-5147. https://doi.org/10.1103/PhysRevLett.80.5145.

[39] P. McMillan, B. Piriou, The structures and vibrational spectra of crystals and glasses in the silica-alumina system, J. Non. Cryst. Solids. 53 (1982) 279-298. https://doi.org/10.1016/0022-3093(82)90086-2.

[40] P.F. McMillan, B.T. Poe, P.H. Gillet, B. Reynard, A study of SiO2 glass and supercooled liquid to $1950 \mathrm{~K}$ via high-temperature Raman spectroscopy, Geochim. Cosmochim. Acta. 58 (1994) 3653-3664. https://doi.org/10.1016/00167037(94)90156-2.

[41] F.L. Galeener, A.J. Leadbetter, M.W. Stringfellow, Comparison of the neutron, Raman, and infrared vibrational spectra of vitreous $\mathrm{SiO} 2, \mathrm{GeO} 2$, and BeF2, Phys. Rev. B. 27 (1983) 1052-1078. https://doi.org/10.1103/PhysRevB.27.1052.

[42] F.A. Seifert, B.O. Mysen, D. Virgo, Three-dimensional network structure of quenched melts (glass) in the systems $\mathrm{SiO} 2--\mathrm{NaAlO} 2, \mathrm{SiO} 2--\mathrm{CaA} 2 \mathrm{O} 4$ and $\mathrm{SiO} 2--\mathrm{MgAl} 2 \mathrm{O} 4$, Am. Mineral. 67 (1982) 696-717.

[43] A. Pasquarello, J. Sarnthein, R. Car, Dynamic structure factor of vitreous silica from first principles: Comparison to neutron-inelastic-scattering experiments, Phys. Rev. B. 57 (1998) 14133-14140. https://doi.org/10.1103/PhysRevB.57.14133.

[44] S. Sen, R.E. Youngman, High-resolution multinuclear NMR structural study of binary aluminosilicate and other related glasses, J. Phys. Chem. B. 108 (2004) 7557-7564.

[45] A. Navrotsky, K.L. Geisinger, G. V Gibbs, The Tetrahedral Framework in Glasses and M e 1 t s - Inferences from Molecular Orbital Calculations and Implications for Structure, Thermodynamics, and Physical Properties, Phys. Chem. (1985) 284-298.

[46] G.M. Bancroft, H.W. Nesbitt, G.S. Henderson, C. O’Shaughnessy, A.C. Withers, D.R. Neuville, Lorentzian dominated lineshapes and linewidths for Raman symmetric stretch peaks $(800-1200 \mathrm{~cm}-1)$ in Qn $(\mathrm{n}=1-3)$ species of alkali silicate glasses/melts, J. Non. Cryst. Solids. 484 (2018) 72-83. https://doi.org/10.1016/j.jnoncrysol.2018.01.018.

[47] H.W. Nesbitt, C. O’Shaughnessy, G.S. Henderson, G. Michael Bancroft, D.R. Neuville, Factors affecting line shapes and intensities of Q3 and Q4 Raman bands of Cs silicate glasses, Chem. Geol. 505 (2019) 1-11. https://doi.org/10.1016/j.chemgeo.2018.12.009.

[48] J. Du, L. Kokou, J.L. Rygel, Y. Chen, C.G. Pantano, R. Woodman, J. Belcher, Structure of cerium phosphate glasses: Molecular dynamics simulation, J. Am. Ceram. Soc. 94 (2011) 2393-2401. https://doi.org/10.1111/j.1551-2916.2011.04514.x. 
659

660

661

662

663

664

665

666

667

668

669

670

671

\section{Tables}

Table 1: Chemical composition (as mol\%) of the codoped core measured by SEM-EDS.

\begin{tabular}{|r|r|r|r|r|}
\hline $\begin{array}{r}\text { Sample } \\
\text { position/label }\end{array}$ & $\mathbf{S i O}_{2}$ & $\mathrm{Al}_{2} \mathbf{O}_{3}$ & $\mathbf{C e O}_{2}$ & $\mathbf{C e O}_{2} / \mathbf{A l}_{2} \mathbf{O}_{3}$ \\
\hline $\mathbf{3 2}$ & 93.7 & 2.6 & 3.71 & 1.44 \\
\hline $\mathbf{2 9}$ & 94.9 & 2.4 & 2.67 & 1.11 \\
\hline $\mathbf{2 4}$ & 95.7 & 2.1 & 2.16 & 1.02 \\
\hline $\mathbf{1 9}$ & 96.1 & 2.0 & 1.87 & 0.93 \\
\hline $\mathbf{1 4}$ & 96.5 & 1.9 & 1.58 & 0.84 \\
\hline $\mathbf{9}$ & 97.4 & 1.6 & 1.03 & 0.63 \\
\hline $\mathbf{4}$ & 98.5 & 1.5 & 0.05 & 0.04 \\
\hline
\end{tabular}

Table 2: Results from the photoluminescence studies. Excitation (Ex) and emission (Em) maxima, and parameters obtained from the deconvolution of the bands with Gaussian (G*) functions are reported. SS: Stokes shifts. All values as $\mathbf{c m}^{-1}$. The $\mathrm{Ce} / \mathrm{Al}$ molar ratios are reported for sake of clarity.

\begin{tabular}{|c|c|c|}
\hline Sample & Excitation & Emission \\
\hline
\end{tabular}

\begin{tabular}{rrrrrrrrrrr}
\hline & Ex max & $\mathrm{G}_{1 \mathrm{Ex}}$ & $\mathrm{G}_{2 \mathrm{Ex}}$ & $\mathrm{G}_{3 \mathrm{Ex}}$ & $\mathrm{Em} \max$ & $\mathrm{G}_{1 \mathrm{Em}}$ & $\mathrm{G}_{2 \mathrm{Em}}$ \\
\hline 32 & 30024 & 29498 & 32160 & 35095 & 24017 & 24741 & 22370 & 2371 & 6007 & 1.44 \\
29 & 30077 & 29524 & 32166 & 34969 & 24452 & 25234 & 22838 & 2396 & 5625 & 1.11 \\
24 & 30235 & 29751 & 32503 & 35268 & 24724 & 25420 & 23112 & 2309 & 5511 & 1.02 \\
19 & 30512 & 29721 & 32235 & 35003 & 24643 & 25363 & 23064 & 2299 & 5869 & 0.93 \\
14 & 30390 & 29638 & 32060 & 34724 & 24709 & 25395 & 23084 & 2311 & 5680 & 0.84 \\
9 & 30816 & 29985 & 32380 & 34931 & 25526 & 26324 & 24142 & 2181 & 5290 & 0.63 \\
4 & 32969 & 30958 & 32531 & 34931 & 27360 & 28164 & 25734 & 2381 & 5609 & 0.04 \\
\hline
\end{tabular}

Table 3: Results of the study of the difference Raman spectra reported in Figure 5E. Ce and Al oxides molar contents are reported for sake of clarity. The position of each peak, the total integrated area of the difference spectra, and the integrated area (as \%) of the two contributions at lower frequencies $\left(\mathbf{P}_{1}+\mathbf{P}_{2}\right)$ are reported.

\begin{tabular}{rccccccccc} 
Sample & $\begin{array}{c}\mathrm{Al}_{2} \mathrm{O}_{3} \\
\text { cladding } \\
\text { mol\% }\end{array}$ & $\begin{array}{c}\mathrm{Al}_{2} \mathrm{O}_{3} \\
\text { core } \\
\mathrm{mol} \%\end{array}$ & $\begin{array}{c}\mathrm{CeO}_{2} \\
\text { core } \\
\mathrm{mol} \%\end{array}$ & $\begin{array}{c}\mathrm{P}_{1} \\
\left(\mathrm{~cm}^{-1}\right)\end{array}$ & $\begin{array}{c}\mathrm{P}_{2} \\
\left(\mathrm{~cm}^{-1}\right)\end{array}$ & $\begin{array}{c}\mathrm{P}_{3} \\
\left(\mathrm{~cm}^{-1}\right)\end{array}$ & $\begin{array}{c}\mathrm{P}_{4} \\
\left(\mathrm{~cm}^{-1}\right)\end{array}$ & $\begin{array}{c}\text { Tot } \\
\text { Integrated } \\
\text { area }\end{array}$ & $\begin{array}{c}\text { \% Int. } \\
\text { Area } \\
\mathrm{P}_{1}+\mathrm{P}_{2}\end{array}$ \\
\hline 32 & 0.03 & 2.58 & 3.71 & 907.5 & 985.2 & 1121.8 & 1200.8 & 3.16 & 74.5 \\
29 & 0.06 & 2.41 & 2.67 & 905.3 & 980.9 & 1115.8 & 1185.5 & 4.13 & 78.1 \\
24 & 0.02 & 2.12 & 2.16 & 926.8 & 985.7 & 1116.5 & 1163.8 & 1.44 & 72.0 \\
19 & 0.02 & 2.00 & 1.87 & 912.2 & 985.6 & 1116.2 & 1180.0 & 2.30 & 65.6 \\
14 & 0.02 & 1.88 & 1.58 & 937.2 & 988.1 & 1116.0 & 1159.5 & 0.90 & 64.0 \\
9 & 0.11 & 1.62 & 1.03 & & 988.5 & 1118.7 & 1176.6 & 0.78 & 49.5 \\
4 & 0.13 & 1.47 & 0.05 & & & $1120.2^{*}$ & & 0.37 & 0.0
\end{tabular}

* Single Lorentzian function. See text for details

673 
Table 4: Results from the Raman signal deconvolution of the Ce/Al codoped cores, in the high-frequency range. Each Gaussian function integrated area $\left(A_{G}\right)$, and total integrated area $\left(A_{t o t}\right)$, along with the Center of mass $(\mathrm{C})$ of the whole $Q$-range are reported. Data obtained for the average Cladding $(\overline{C l a d})$ and

678 reference $\mathrm{SiO}_{2}$ are reported for comparison.

\begin{tabular}{|c|c|c|c|c|c|c|c|c|c|c|c|c|c|}
\hline Sample & $\begin{array}{c}\mathrm{Ce} / \mathrm{A} \\
1 \\
\end{array}$ & $\begin{array}{c}\mathrm{G}^{1} \\
\left(\mathrm{~cm}^{-1}\right)\end{array}$ & $A_{G^{1}}$ & $\begin{array}{c}\mathrm{G}^{2} \\
\left(\mathrm{~cm}^{-1}\right)\end{array}$ & $A_{G^{2}}$ & $\begin{array}{c}\mathrm{G}^{3} \\
\left(\mathrm{~cm}^{-1}\right)\end{array}$ & $A_{G^{3}}$ & $\begin{array}{c}\mathrm{G}^{4} \\
\left(\mathrm{~cm}^{-1}\right)\end{array}$ & $A_{G^{4}}$ & $\begin{array}{c}\mathrm{G}^{5} \\
\left(\mathrm{~cm}^{-1}\right)\end{array}$ & $A_{G^{5}}$ & $\begin{array}{c}\mathrm{A}_{\text {to }} \\
\mathrm{t}\end{array}$ & $\mathrm{C}\left(\mathrm{cm}^{-1}\right)$ \\
\hline 32 & 1.44 & 1051.5 & 42.3 & 1153.4 & 19.7 & 1211.1 & 13.3 & 915.8 & 8.0 & 972.0 & 16.7 & 3.9 & 1068.8 \\
\hline 29 & 1.11 & 1054.5 & 40.9 & 1151.0 & 18.3 & 1210.9 & 10.4 & 919.7 & 11.2 & 978.5 & 19.2 & 5.1 & 1058.7 \\
\hline 24 & 1.02 & 1054.0 & 46.0 & 1143.2 & 17.2 & 1203.1 & 16.6 & 924.1 & 9.9 & 979.3 & 10.3 & 4.1 & 1073.5 \\
\hline 19 & - & 1055.1 & 45.6 & 1157.7 & 29.5 & 1218.5 & 6.6 & 917.7 & 6.1 & 972.5 & 12.3 & 4.7 & 1077.5 \\
\hline 14 & 0.84 & 1060.6 & 51.9 & 1154.6 & 21.9 & 1211.0 & 11.3 & 919.5 & 5.5 & 977.4 & 9.3 & 3.6 & 1082.8 \\
\hline 9 & 0.63 & 1061.5 & 52.6 & 1147.4 & 21.0 & 1206.2 & 17.4 & 927.3 & 5.2 & 978.3 & 3.7 & 3.9 & 1094.7 \\
\hline 4 & 0.04 & 1058.0 & 45.7 & 1132.8 & 27.1 & 1203.5 & 27.2 & - & - & - & - & 3.0 & 1117.9 \\
\hline$\overline{\text { Clad }^{\S}}$ & - & 1059.9 & 55.8 & 1159.4 & 21.3 & 1212.9 & 23.0 & - & - & - & - & 2.7 & 1116.2 \\
\hline $\mathrm{SiO}_{2}$ & - & 1059.4 & 53.8 & 1161.5 & 20.6 & 1212.9 & 25.6 & - & - & - & - & 2.1 & 1119.7 \\
\hline
\end{tabular}

$679 \S$ Average signal of all cladding portions analyzed.

680

681 
682

683

684

685

686

687

688

689

690

691

692

693

694

695

696

697

698

699

700

701

702

703

704

705

706

707

708

709

710

711

712

713

714

715

716

\section{Figures Caption}

Figure 1: Schematic drawing of the core portion of the $\mathrm{SiO}_{2}$ preform (silica cladding not represented). Each bold number indicates the position where the disks have been cut $(\mathrm{cm})$ along the preform, which also represents samples labeling. Darker color indicates a higher $\mathrm{CeO}_{2}$ content. On top is reported the $\mathrm{CeO}_{2} / \mathrm{Al}_{2} \mathrm{O}_{3}$ molar ratio in the codoped core.

Figure 2: Normalised excitation (Ex) and emission (Em) spectra for the different samples, and deconvoluted Gaussian bands. By increasing the $\mathrm{CeO}_{2}$ molar content both Ex and Em bands show a red shift, and an increase of Stokes shifts and of the ground level splitting. The luminescence properties of sample 4 are different. See text for details.

Figure 3: Photoluminescence spectra collected in the codoped cores are compared to the most intense signals observed in the cladding (grey solid lines). Black vertical arrows indicate the Ex and Em wavelength used to collect the signals in the codoped core samples. For the cladding, two emission bands are reported, one collected with an excitation wavelength $(\lambda \mathrm{Em})$ of $300 \mathrm{~nm}$ (close to the Ex maximum of sample 4 - orange vertical arrow), and the other one collected at $350 \mathrm{~nm}$ (grey vertical arrow).

Figure 4: (a) Normalized excitation spectra for samples 4 and 32 (black solid lines) and Gaussian bands used for signal deconvolution (dotted lines). The Emission spectra (colored solid lines) were collected at different excitation wavelengths marked by the vertical arrows.

Figure 5: Raman spectra collected in the cladding (A), and in the codoped core (B) of the different disks. A) The Raman spectrum of pure $\mathrm{SiO}_{2}$ glass (dashed black line) is compared to signals from the cladding portions .B) An average spectra of all claddings $(\overline{\text { Clad }}$, black solid line) is reported as reference and compared to the core signals. Insets provide a magnification of the $D_{2}$ defect line, and of the $Q$-range.

Figure 6: A-C) Raman spectra collected in the core region and the subtracted spectra obtained by the difference between core and cladding of the same sample. Magnifications of the defect lines and of the $Q$-range are reported, respectively, in panel B and C. In A, a Cladding spectrum is reported as reference in black. D) Example of the subtractive method used. The Raman signal of each cladding has been subtracted to the one collected into the core region. The difference spectrum obtained has been deconvoluted with mathematical functions, and 
717 based on their positions we use the labels $\mathrm{P}_{1}, \mathrm{P}_{2}, \mathrm{P}_{3}$ and $\mathrm{P}_{4}$. E) Stacked difference spectra and 718 position of the mathematical functions for some of the samples.

719

720 Figure 7: Details of the Raman spectra and deconvolution of the high-frequency regions of

721 some of the samples investigated. In the codoped core, for $\mathrm{CeO}_{2}$ contents $\geq 1 \mathrm{~mol} \%$, two

722 additional vibrations rise, respectively at $\sim 916 \mathrm{~cm}^{-1}$ and $\sim 970 \mathrm{~cm}^{-1}$. The chemical

723 compositions of both cladding and core are reported for sake of clarity (as mol\% oxide).

724

725 Figure 8: Correlations between parameters from Raman data analysis and Photoluminescence

726 studies of the codoped cores. A) the Raman center of mass C vs. the Emission (Em) and

727 Excitation (Ex) maxima. B) the frequency Excitation maxima are related to the sum of the

728 integrated areas of the contributions $\mathrm{P}_{1}$ and $\mathrm{P}_{2}$, obtained following the subtractive method. The

729 latter shows a nearly perfect linear correlation (Adjusted $\mathrm{R}^{2}=99.92$ ).

730

731

732 


\section{Figure 1}

\begin{tabular}{|c|l|l|l|l|l|l|l|}
$\mathrm{CeO}_{2} / \mathrm{Al}_{2} \mathrm{O}_{3}$ & 0.04 & 0.63 & 0.84 & & 1.02 & 1.11 & 1.44 \\
\hline $\begin{array}{r}\text { Core preform } \\
\text { Position }(\mathrm{cm}) \\
\text { Sample name }\end{array}$ & $\mathbf{4}$ & & & & & & \\
\hline
\end{tabular}

734

735 
736 Figure 2
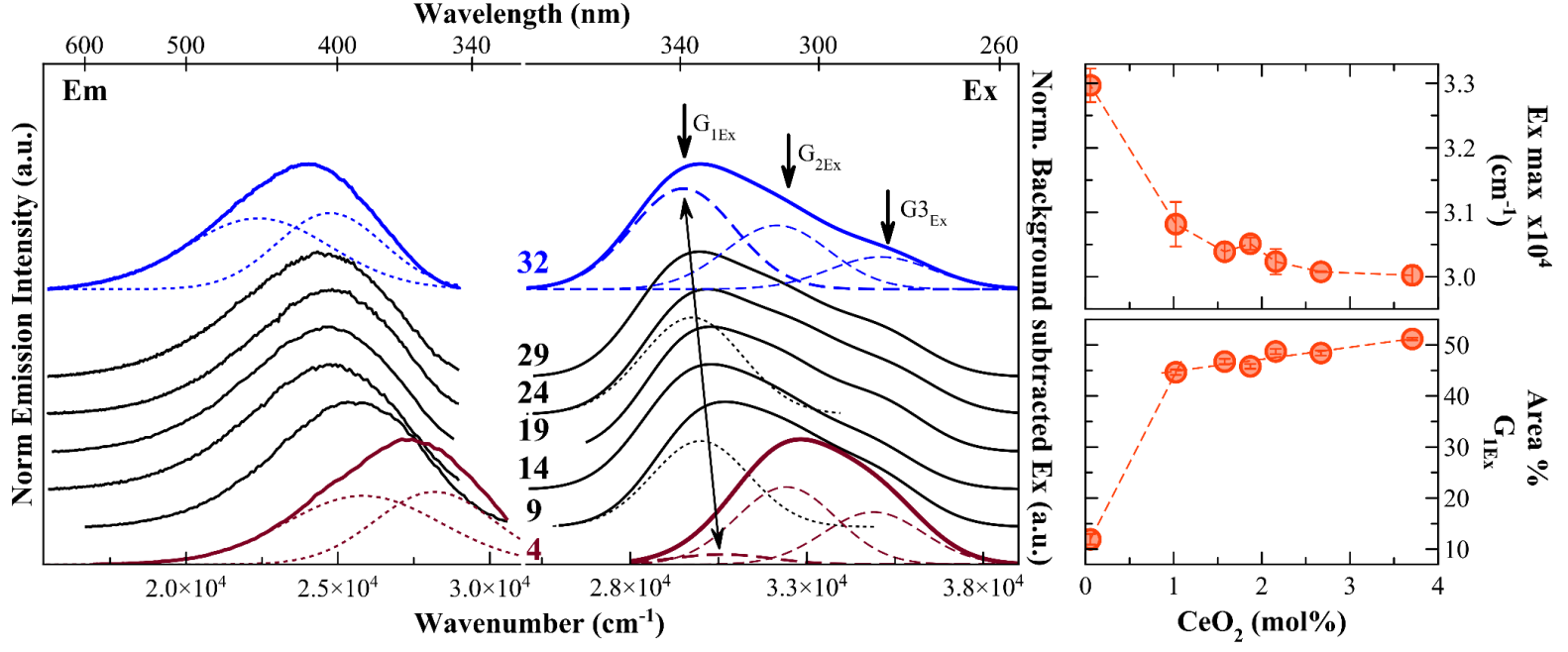
$739 \quad$ Figure 3

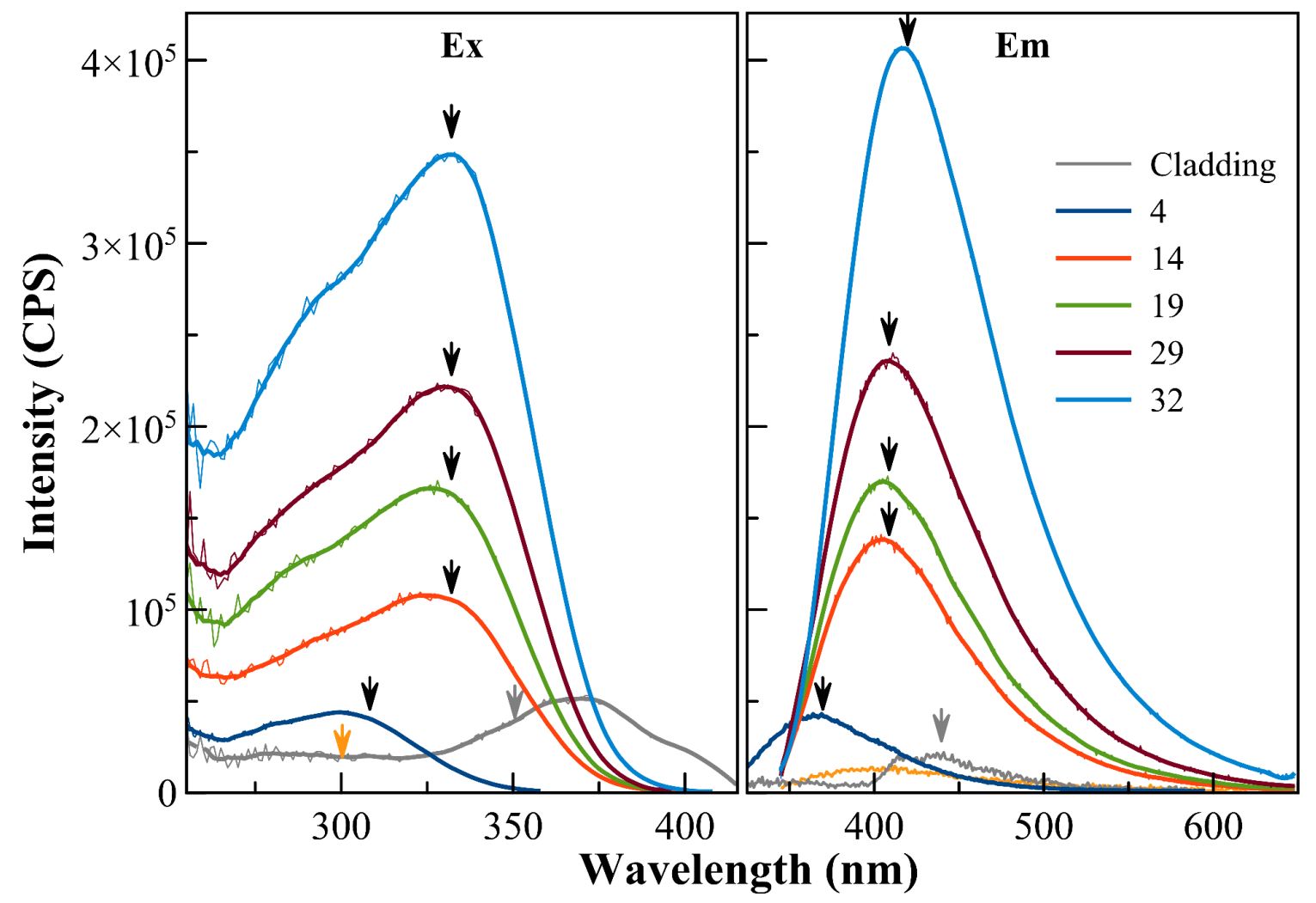


$742 \quad$ Figure 4
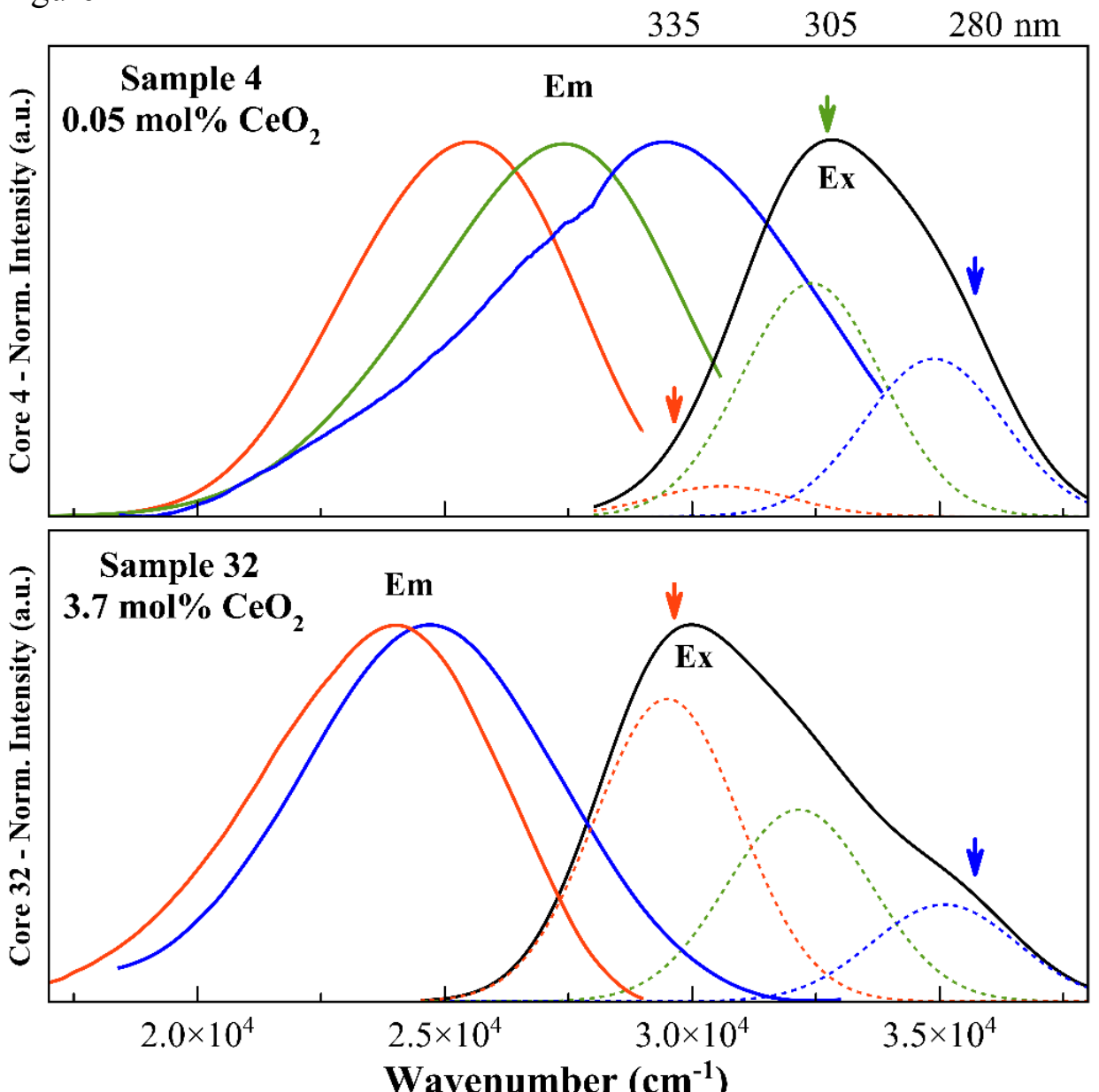
$745 \quad$ Figure 5
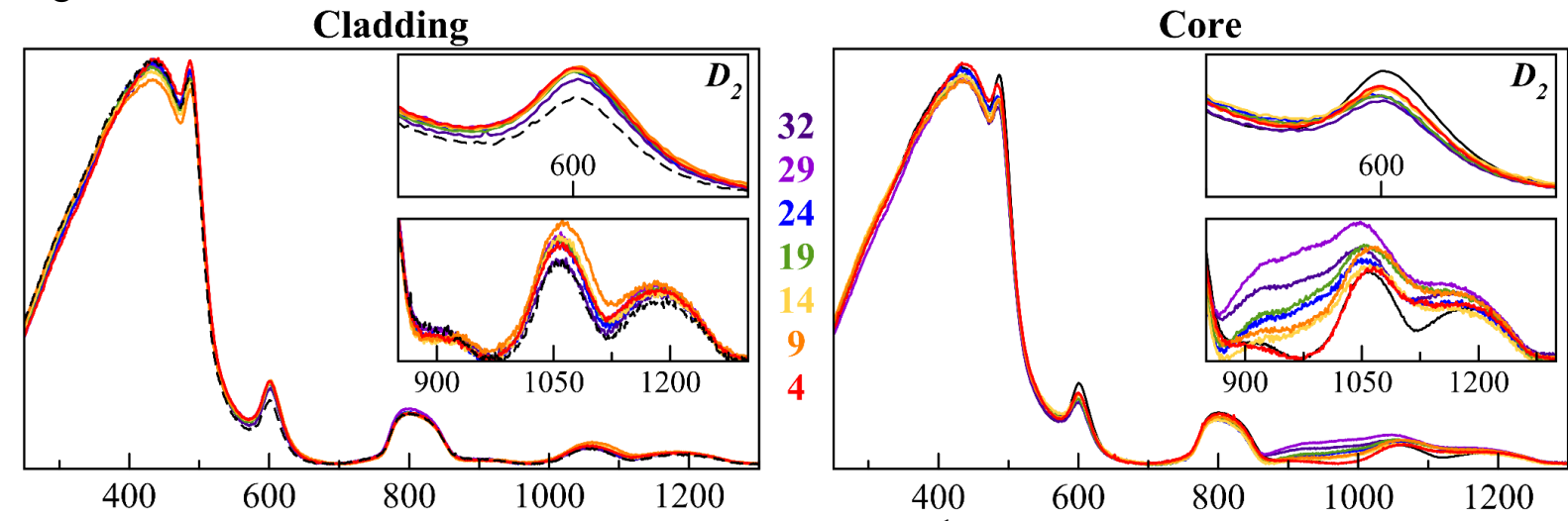

746

Raman shift $\left(\mathrm{cm}^{-1}\right)$

747 
$748 \quad$ Figure 6
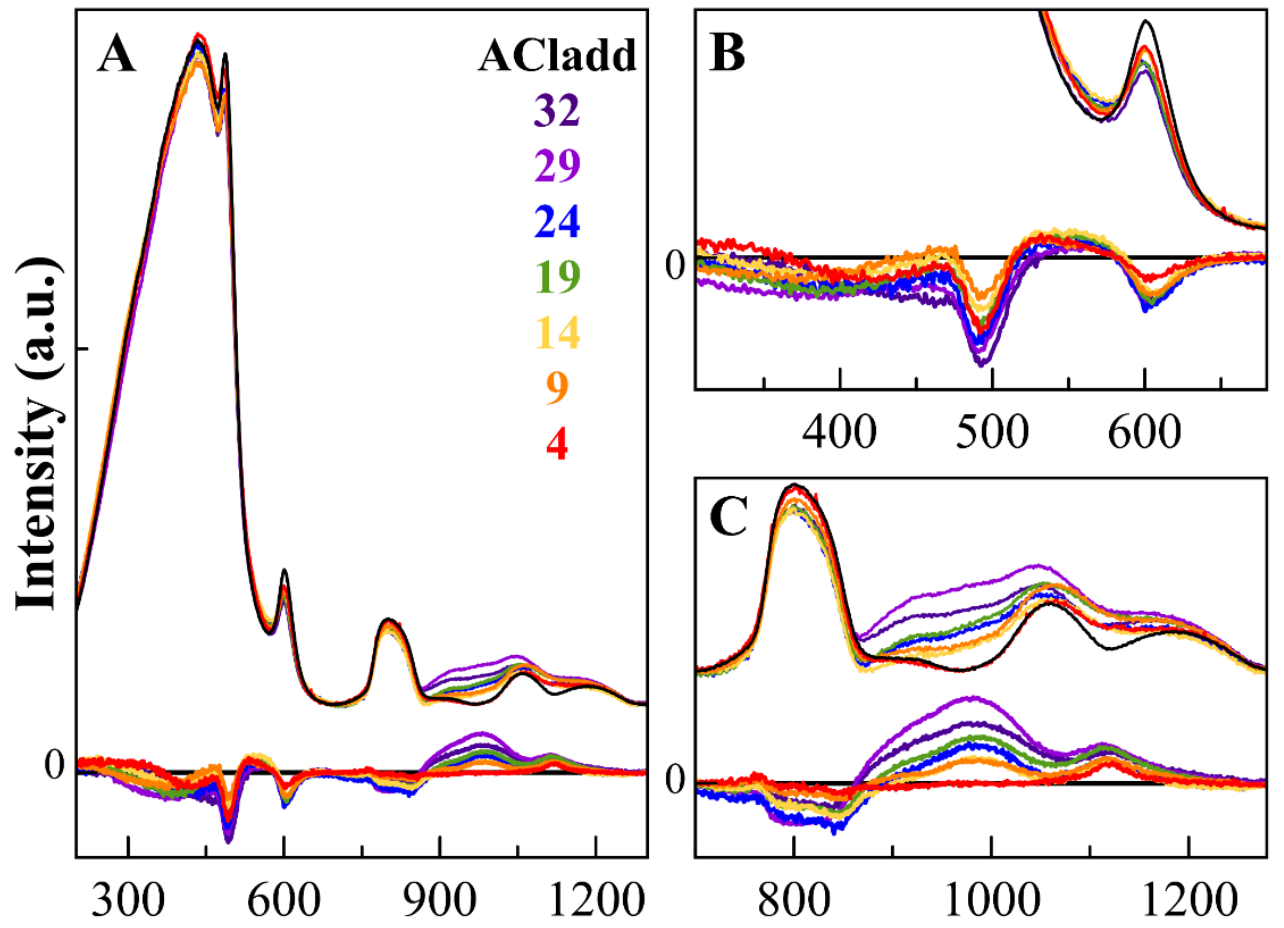

Raman shift $\left(\mathrm{cm}^{-1}\right)$
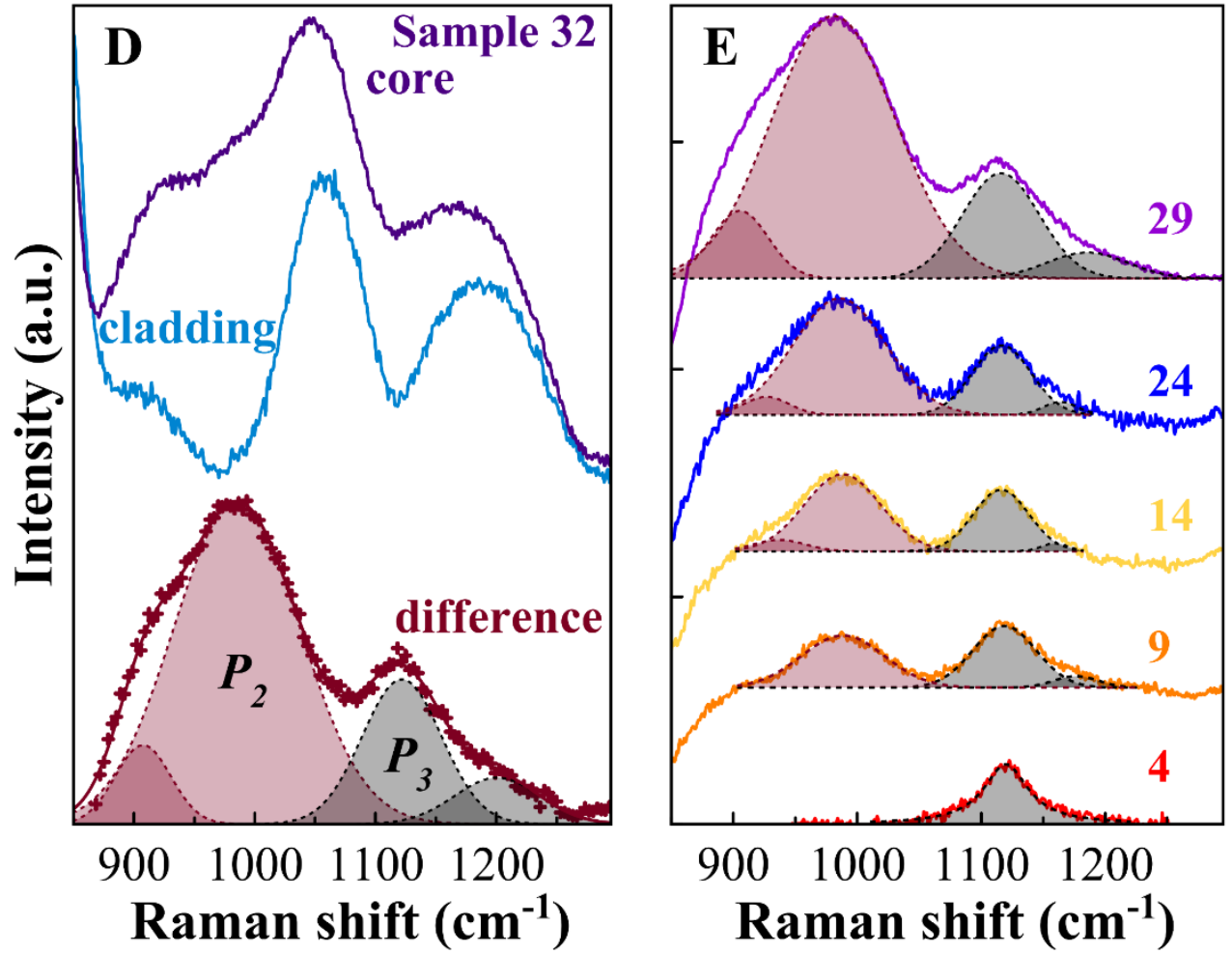
$751 \quad$ Figure 7

SAMPLE 4

SAMPLE 9

SAMPLE 14

SAMPLE 24

SAMPLE 29
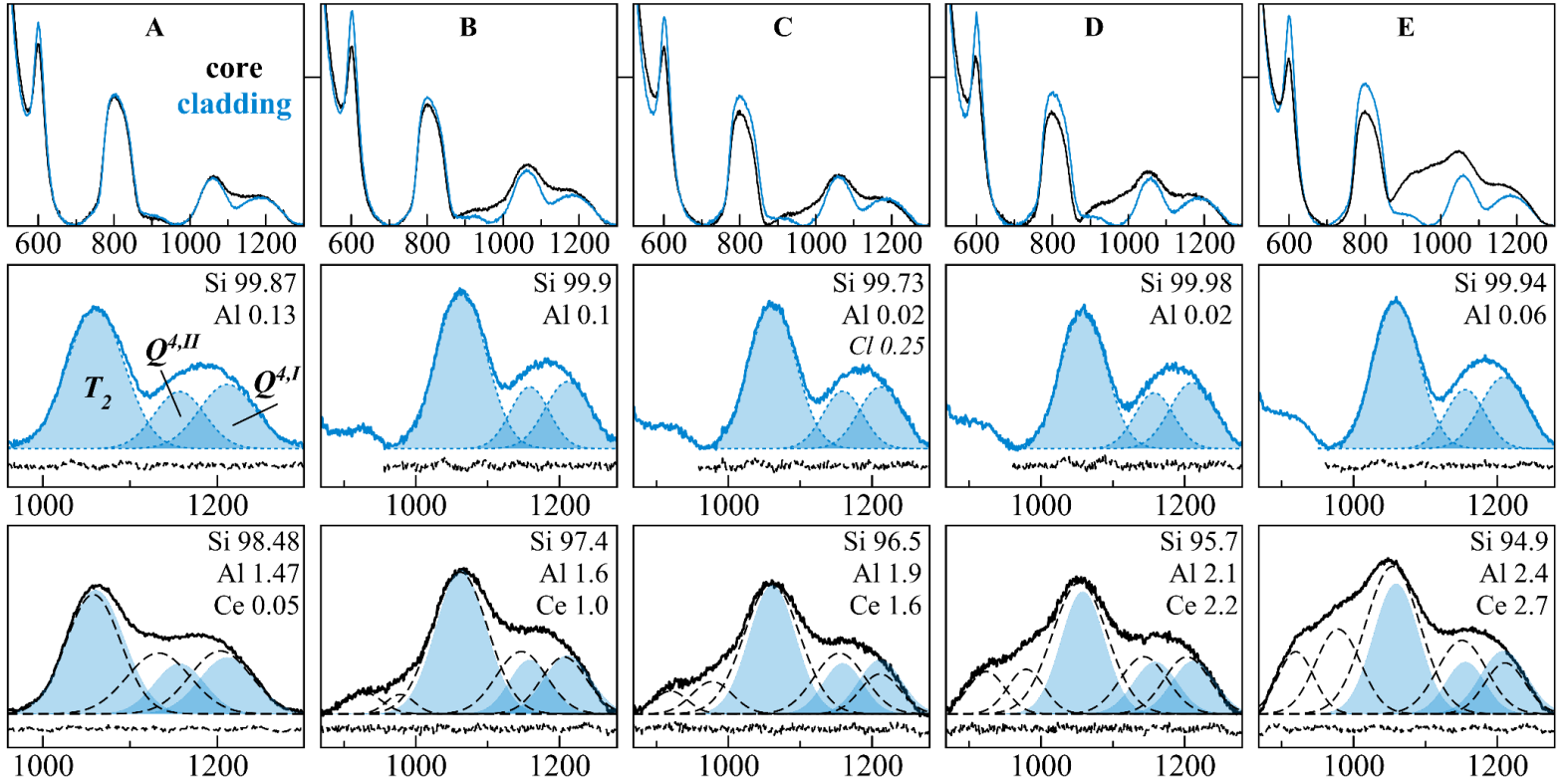

752

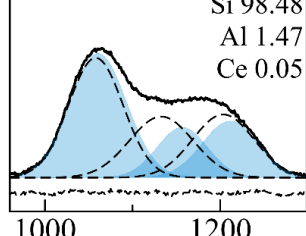

753

Raman shift ( $\left.\mathrm{cm}^{-1}\right)$

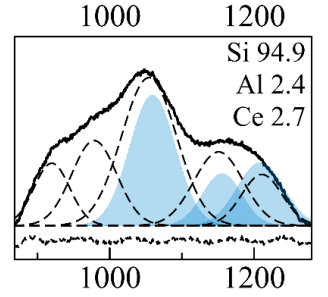


$754 \quad$ Figure 8

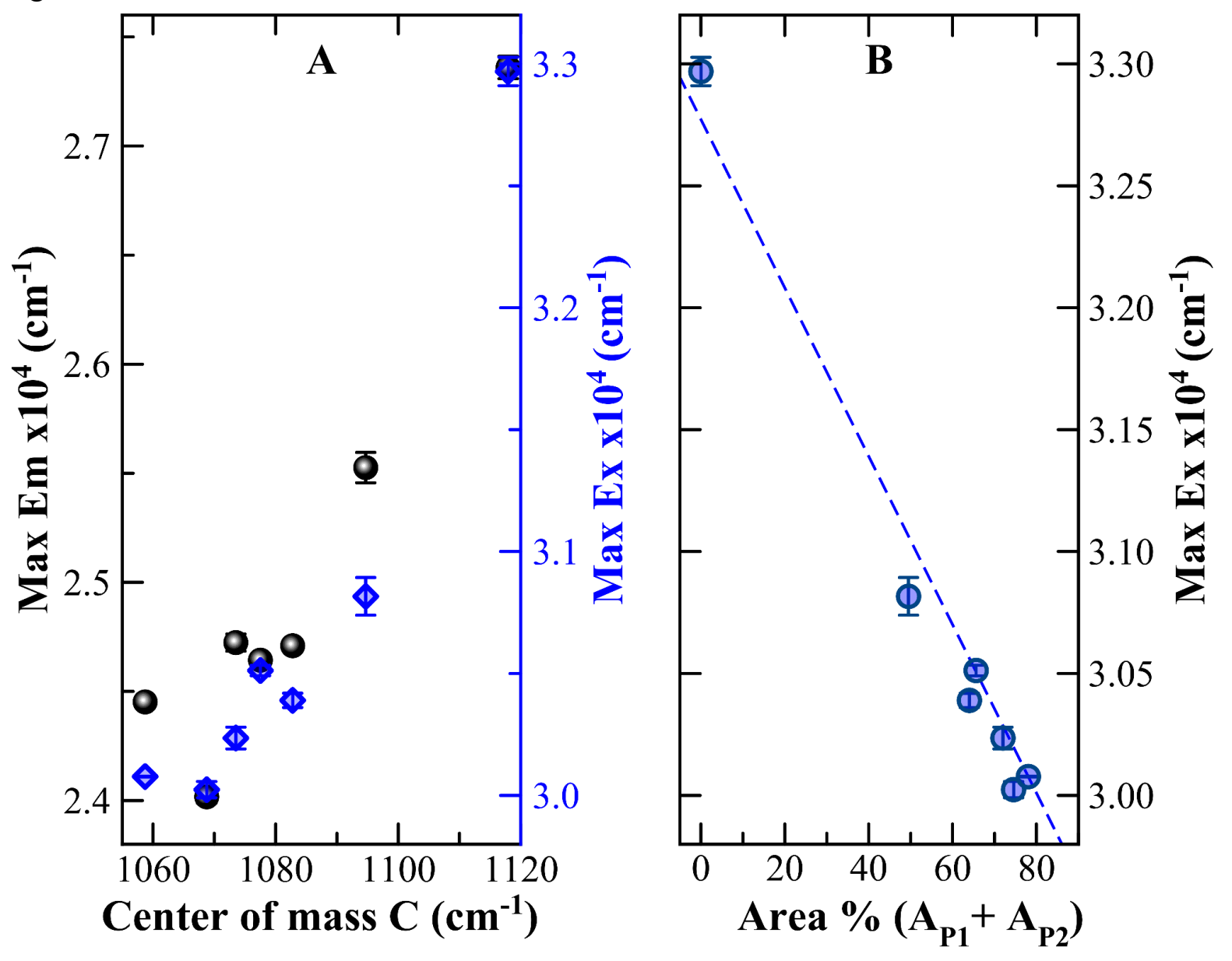

